\title{
Sepse associada ao cateter venoso central em pacientes adultos internados em
}

\section{Unidade de Terapia Intensiva}

Sepsis associated with central venous catheters in adult patients admitted to the Intensive Care Unit Sepsis asociada a catéteres venosos centrales en pacientes adultos ingresados en la Unidad de Cuidados Intensivos

Airton César Leite ORCID: https://orcid.org/0000-0001-7184-8488 Centro Universitário Santo Agostinho, Brasil E-mail: ainton.cesar2014@gmail.com

Mariana Pereira Barbosa Silva ORCID: https://orcid.org/0000-0003-0852-8099

Universidade Estadual do Piauí, Brasil E-mail: marianapbsilvaa@gmail.com

Geovana Maria Rodrigues de Sousa ORCID: https://orcid.org/0000-0001-6398-8560

Centro Universitário Santo Agostinho, Brasil E-mail: geovanamaria08@hotmail.com

Samuel Lopes dos Santos ORCID: https://orcid.org/0000-0003-3375-9171 Universidade Federal do Piauí, Brasil

E-mail: samuellopes121314@gmail.com

Diego Bruno Brito Cerqueira ORCID: https://orcid.org/0000-0002-8083-1634 Faculdade Integral Diferencial, Brasil

E-mail: diegocerqueirafisioterapeuta@hotmail.com

Winícius de Carvalho Alves

ORCID: https://orcid.org/0000-0003-3118-5696

Centro Universitário Santo Agostinho, Brasil

E-mail: winiciusdecarvalho@ hotmail.com

Cilmara Gomes Martins da Silva

ORCID: https://orcid.org/0000-0002-9415-4099 Faculdade de Tecnologia e Educação Superior Profissional, Brasil E-mail: silmaragomes09@ outlook.com

Erica Williams de Moreira Lima ORCID: https://orcid.org/0000-0003-3957-5699

Centro Universitário Uninovafapi, Brasil

E-mail: williams-erica1992@outlook.com

Célio Pereira de Sousa Júnior

ORCID: https://orcid.org/0000-0003-0726-0668 Universidade Federal do Pará, Brasil E-mail: academicocelio@gmail.com

Antônio Filho Alves Rodrigues ORCID: https://orcid.org/0000-0001-7714-9901 Universidade Federal do Piauí, Brasil E-mail: filho.nino@hotmail.com

Mariana Tenório Costa

ORCID: https://orcid.org/0000-0001-8116-4864 Centro Universitário Tiradentes, Brasil E-mail: mtc0809@hotmail.com

Jéssica Lara Cipriano Santos

ORCID: https://orcid.org/0000-0002-9710-7212 Centro Universitário Tiradentes, Brasil E-mail: jessicalcsantoos@ gmail.com Weberton Dorásio Sobrinho

ORCID: https://orcid.org/0000-0003-0619-7214

Universidade de Rio Verde, Brasil E-mail: dorasioweberton@gmail.com 
Laiana Dias Prudêncio

ORCID: https://orcid.org/0000-0002-0016-3868 Centro Universitário Maurício de Nassau, Brasil E-mail: laianadias568@gmail.com

Raimunda da Silva Sousa Neta

ORCID: https://orcid.org/0000-0001-5927-0046 Centro Universitário Santo Agostinho, Brasil E-mail: raynettasousa@gmail.com

Sarah Maria Osório de Carvalho

ORCID: https://orcid.org/0000-0002-6396-7775 Centro Universitário Santo Agostinho, Brasil E-mail: sarahosorio34@gmail.com

Maria dos Milagres Santos da Costa

ORCID: https://orcid.org/0000-0002-2290-5914 Associação de Ensino Superior do Piauí, Brasil E-mail: maramsantos1010@gmail.com

Tágila Andreia Viana dos Santos ORCID: https://orcid.org/0000-0001-9812-4295 Faculdade de Tecnologia e Educação Superior Profissional, Brasil E-mail: tagylla03@gmail.com

Yasmim Vieira dos Santos

ORCID: https://orcid.org/0000-0002-6661-7383 Centro Universitário Maurício de Nassau, Brasil

E-mail: mimsayvieira@gmail.com

Bianca Barroso de Sousa

ORCID: https://orcid.org/0000-0002-3521-6667 Universidade Estadual do Maranhão, Brasil E-mail: biancabarroso000@gmail.com

Mateus Silva Soares

ORCID: https://orcid.org/0000-0002-5562-4908

Faculdade de Educação São Francisco, Brasil E-mail: mateussilva8945@gmail.com

Joelma Maria dos Santos da Silva Apolinário

ORCID: https://orcid.org/0000-0001-9521-9432 Faculdade Maurício de Nassau, Brasil E-mail: jo.silva00@hotmail.com

Beatriz Cristina Carvalho Macêdo

ORCID: https://orcid.org/0000-0003-3756-2624 Centro Universitário Uninovafapi, Brasil E-mail: beatrizmaccedo1 @gmail.com

Rebeca Nunes Martins de Oliveira Machado ORCID: https://orcid.org/0000-0002-4767-8965 Universidade Federal do Piauí, Brasil E-mail: rebecanunes96@outlook.com

\title{
Resumo
}

Analisar as evidências científicas publicadas sobre os fatores para o desenvolvimento de sepse associada ao cateter venoso central em pacientes adultos internados em Unidade de Terapia Intensiva. O presente estudo trata de uma revisão bibliográfica do método revisão integrativa da literatura, realizado nos meses entre junho a novembro de 2021. A busca efetuou-se, através da - BVS, utilizando as bases de dados Literatura LILACS, BDENF, por meio da SCIELO. Aderindo-se através dos descritores/palavras chaves: "Sepse", "Cateter venoso central", "Unidade de Terapia Intensiva", combinados com o operador booleano "AND”. As infecções hospitalares são as principais causas de morte nas unidades de terapia intensiva, representando uma ampliação no tempo de internação, além de um custo elevado para as instituições, por agregar inúmeros fatores de risco como: condições clínicas desfavoráveis, comorbidades, uso de técnicas invasivas e alterações na microbiota. A assistência aos pacientes críticos requer a inevitável aplicação de procedimentos invasivos e a administração de antimicrobianos de amplo espectro, sendo importante assim a redobrada atenção de todos os profissionais envolvidos quanto ao uso de técnicas cada vez mais assépticas, a lavagem rotineira das mãos e o uso controlado e estritamente necessário de técnicas invasivas e de antibióticos na rotina dos cuidados. A atuação precisa do enfermeiro, mediante a identificação de padrões anormais de saúde e o reconhecimento precoce constitui-se uma das principais formas de aplicação dos cuidados de enfermagem, tendo em vista que, após instalação da doença, quanto mais precisa e rápida ocorrer às ações de saúde, menores serão as chances de progressão e gravidade da doença e, consequentemente, melhor será o prognóstico.

Palavras-chave: Sepse; Cateter venoso central; Unidade de terapia intensiva.

\begin{abstract}
To analyze published scientific evidence on factors for the development of sepsis associated with central venous catheters in adult patients admitted to the Intensive Care Unit. The present study is a literature review of the
\end{abstract}


integrative literature review method, carried out in the months between June and November 2021. The search was carried out through the - VHL, using the Literature databases LILACS, BDENF, through - SCIELO. Adhering through the descriptors/key words: "Sepsis", "Central venous catheter", "Intensive Care Unit", combined with the Boolean operator "AND". Nosocomial infections are the main causes of death in intensive care units, representing an increase in the length of hospital stay, in addition to a high cost for institutions, by adding numerous risk factors such as: unfavorable clinical conditions, comorbidities, use of invasive techniques and changes in the microbiota. The care of critically ill patients requires the inevitable application of invasive procedures and the administration of broadspectrum antimicrobials, so it is important that all professionals involved pay extra attention to the use of increasingly aseptic techniques, routine hand washing and the use of controlled and strictly necessary invasive techniques and antibiotics in routine care. the precise role of the nurse, through the identification of abnormal health patterns and early recognition, constitutes one of the main ways of applying nursing care, considering that, after the disease onset, the more precise and faster the actions occur. health conditions, the lower the chances of progression and severity of the disease and, consequently, the better the prognosis.

Keywords: Sepsis; Central venous catheter; Intensive care unit.

\section{Resumen}

Analizar la evidencia científica publicada sobre factores para el desarrollo de sepsis asociada a catéteres venosos centrales en pacientes adultos ingresados en la Unidad de Cuidados Intensivos. Este estudio es una revisión bibliográfica del método de revisión integradora de la literatura, realizada entre junio y noviembre de 2021 . La búsqueda se realizó a través de la BVS, utilizando las bases de datos de literatura (LILACS), (BDENF), a través de (SCIELO). Adhiriéndose a los descriptores / palabras clave: "Sepsis", "Catéter venoso central", "Unidad de Cuidados Intensivos", combinado con el operador booleano "Y". Las infecciones nosocomiales son las principales causas de muerte en las unidades de cuidados intensivos, representando un aumento en la duración de la estancia hospitalaria, además de un alto costo para las instituciones, al agregar numerosos factores de riesgo como: condiciones clínicas desfavorables, comorbilidades, uso de técnicas invasivas y cambios en la microbiota. La atención al paciente crítico requiere la inevitable aplicación de procedimientos invasivos y la administración de antimicrobianos de amplio espectro, por lo que es importante que todos los profesionales involucrados presten especial atención al uso de técnicas cada vez más asépticas, al lavado de manos rutinario y al uso de métodos controlados y estrictos. técnicas invasivas necesarias y antibióticos en la atención de rutina. El papel preciso del enfermero, a través de la identificación de patrones anormales de salud y el reconocimiento temprano, constituye una de las principales formas de aplicar los cuidados de enfermería, considerando que, luego del inicio de la enfermedad, cuanto más precisas y rápidas ocurren las acciones. Disminuyen las posibilidades de progresión y gravedad de la enfermedad y, en consecuencia, mejor es el pronóstico.

Palabras clave: Septicemia; Catéter venoso central; Unidad de terapia intensiva.

\section{Introdução}

As Unidades de Terapia Intensiva (UTIs) são setores designados a prestar assistência de alta complexidade a pacientes em estado crítico de saúde. Quando são admitidos nessas unidades necessitam de tratamento e cuidados específicos e, frequentemente, são expostos a procedimentos invasivos, sendo um dos principais a inserção do Cateter Venoso Central (CVC). O CVC é extremamente importante na assistência à saúde. Pelas seguintes indicações: realização de hemodiálise, infusão de nutrição parenteral, quimioterapia, transplante de medula óssea, terapia endovenosa, monitorização hemodinâmica e é essencial para o tratamento e a assistência de enfermagem principalmente em UTI (Neto, Dias, Ribeiro, \& Lima, 2020).

Os cateteres venosos centrais (CVCs) são acessos vasculares utilizados para infusão de medicações, soluções endovenosas, hemoderivados e quimioterápicos em pacientes com limitação de acesso venoso periférico e, ainda, para nutrição parenteral prolongada, monitorização hemodinâmica invasiva da pressão sanguínea arterial, pressão venosa central, pressão da artéria pulmonar, medição de débito cardíaco e acesso para hemodiálise. Embora o CVC forneça acesso vascular seguro, as práticas inadequadas em seu manuseio podem acarretar em maior risco de diversas complicações para os pacientes incluindo a ICSRC (Sousa, Pereira, Rezende, \& Laura, 2018).

Segundo o Journal of American Medical Association, a sepse é definida como uma disfunção de órgãos, com risco de vida, causada por uma resposta desregulada do hospedeiro à infecção. É como uma síndrome clínica que apresenta anormalidades fisiológicas, biológicas e bioquímicas causadas por uma resposta inflamatória desregulada à infecção. A sepse e 
a resposta inflamatória que se segue podem levar à síndrome de disfunção de múltiplos órgãos e à morte (Reiner, Vietta, Vignardi, Gama, \& Klingelfus, 2020).

De acordo com Filho, Marinho e Santos (2018), a sepse é um conjunto de reações inflamatórias, neurais, hormonais e metabólicas, conhecidas como Síndrome da Resposta Inflamatória Sistêmica (SIRS) resultante de uma complexa interação entre o microorganismo infectante e a resposta imune, pró-inflamatória e pró-coagulante do hospedeiro. Sepse, sepse grave ou choque séptico representam a evolução temporal da mesma síndrome com espectros distintos de gravidade associados a taxas crescentes de mortalidade.

A sepse é um grave problema de saúde pública em Unidade de Terapia Intensiva (UTI), que apesar de um enorme esforço de investigação nas últimas décadas continua sendo um desafio considerável e crescente aos cuidados de saúde. No Brasil, esta patologia é a segunda principal causa de mortalidade em UTI, tendo a incidência aumentada de 82,7 casos em 100.000 habitantes em 1979 para 240,4 por 100.000 em 20004, com a mortalidade hospitalar variando entre 28 a $60 \%$ de acordo com a gravidade da doença. A incidência no Brasil é de aproximadamente 200 mil casos por ano, com uma mortalidade entre 35 a $45 \%$ para sepse grave, e 52 a $65 \%$ para o choque séptico. Com a evolução de tratamentos mais agressivos e a melhora da sobrevida de pacientes com doenças crônicas e graves, observa-se maior tempo de hospitalização de pessoas portadoras dessas doenças e aumento da incidência de sepse (Barros, Maia, \& Monteiro, 2016).

A sepse representa uma das maiores causas de hospitalização e mortalidade nas Unidades de Terapia Intensiva (UTI) de todo o mundo, estando diretamente associada às respostas inflamatórias sistêmicas graves, secundárias à infecção e caracterizando, dessa maneira, uma síndrome clínica relacionada às múltiplas possibilidades de uma complexa interação entre o microrganismo infectante e a resposta imune, pró-inflamatória e pró-coagulante do hospedeiro (Neto, Campos, Marques, Ramalho, \& Nóbrega, 2015).

Apesar da disponibilidade dos modernos recursos diagnósticos, do uso de antibióticos de largo espectro, da monitorização hemodinâmica à beira do leito, do controle metabólico intensivo e das novas abordagens terapêuticas, a sepse se manifesta em distintos espectros de gravidade com o decorrer do tempo (sepse grave, choque séptico e disfunção de múltiplos órgãos e sistemas) caso não seja prontamente diagnosticada e tratada, representando altos custos anuais em seu tratamento. No ambiente de cuidados intensivos, há um risco aumentado para desenvolvê-la devido aos vários fatores relevantes para o seu desencadeamento, como as doenças predisponentes do paciente crítico e o grau de severidade; o tempo de internação prolongado e debilitante, principalmente nos pacientes idosos; a prevalência mais acentuada de resistência bacteriana; os diversos procedimentos invasivos, como a intubação endotraqueal e a necessidade de ventilação mecânica, os acessos intravasculares, a sondagem vesical e outras intervenções que ocasionam a quebra das barreiras naturais do organismo (Neto, Campos, Marques, Ramalho, \& Nóbrega, 2015).

É de suma importância identificar quais são os fatores de risco que estão ocasionando sepse pelo CVC dentro das UTIs, para poder entender o que está acontecendo de incorreto e em seguida corrigir, assim tende a diminuir e evitar os casos por esse agravo além dos óbitos e custos financeiros. Os pacientes desenvolvem essa patologia devido a ICS pelo CVC, por causa da quebra da técnica asséptica na hora da inserção e manutenção do CVC, onde ocorre à falta do uso de luvas estéreis, máscara e toca, uma limpeza incorreta, produtos usados não indicados na troca de curativos, manuseio excessivo, a idade, contaminação dos hubs, nutrição parenteral, tempo de duração do cateterismo e da internação, infusão de fluidos contaminados, falta de educação continuada da equipe de enfermagem, falta da implementação de protocolos para saber identificar o problema e realizar o tratamento adequado (Martins, Sandim, Felipe, \& Sousa, 2020).

O profissional de enfermagem exerce um papel importante perante o cuidado aos pacientes críticos internados na UTI, no cenário da sepse tem papel fundamental, atuando na prevenção, identificação e tratamento. Logo, levando em consideração a rápida evolução da doença e a gravidade que compete, é essencial que os profissionais atuem no 
reconhecimento dos fatores de risco da sepse e predisposição de cada paciente, possibilitando implementar um plano de cuidado assertivo na prevenção do agravo. O Enfermeiro, sempre presente na beira do leite pode e deve discutir com a equipe de enfermagem as intervenções e as condutas a serem realizadas para a melhor recuperação do cliente. A equipe unida e focada no mesmo objetivo, ajudar a reduzir os altos índices de morbidade e de mortalidade de sepse, e choque séptico, onde a avaliar os fatores de riscos pode ajudar a identificar os pacientes que necessitam de uma maior vigilância possível (Aguiar, Cruz, Silva, Sousa, \& Moraes, 2020).

Diante da temática em discussão, surge como questão norteadora do estudo: "Quais os fatores para o desenvolvimento de sepse associada ao cateter venoso central em pacientes adultos internados em Unidade de Terapia Intensiva"? Assim, o objetivo do presente estudo é analisar as evidências científicas publicadas sobre os fatores para o desenvolvimento de sepse associada ao cateter venoso central em pacientes adultos internados em Unidade de Terapia Intensiva.

A realização do presente estudo relacionado à temática, é essencial para a construção coletiva do conhecimento, pois, o estudo possibilita a sociedade acadêmica e cientifica a ampliar o conhecimento sobre os fatores para o desenvolvimento de sepse associada ao cateter venoso central em pacientes adultos internados em Unidade de Terapia Intensiva. Desse modo, o estudo trará contribuições pertinentes, na medida em que acrescentará as evidências científicas discussões relevantes a respeito dessa temática tão importante.

\section{Metodologia}

O presente estudo trata de uma revisão bibliográfica do método revisão integrativa da literatura, realizado nos meses entre junho a novembro de 2021. A revisão configura-se, portanto, como um tipo de revisão da literatura que reúne achados de estudos desenvolvidos mediante diferentes metodologias, permitindo aos revisores sintetizar resultados sem ferir a filiação epistemológica dos estudos empíricos incluídos. Para que esse processo concretize-se de maneira lógica, isenta de desatinos epistemológicos, a revisão requer que os revisores procedam à análise e à síntese dos dados primários de forma sistemática e rigorosa (Soares et al., 2014).

A revisão da literatura serve para reconhecer a unidade e a diversidade interpretativa existente no eixo temático em que se insere o problema em estudo, para ampliar, ramificar a análise interpretativa, bem como para compor as abstrações e sínteses que qualquer pesquisa requer colaborando para a coerência nas argumentações do pesquisador. Nesse sentido, a revisão integrativa é um método que tem como finalidade reunir e sintetizar resultados de pesquisas sobre um delimitado tema ou questão, de maneira sistemática e ordenada e abrangente, contribuindo para o aprofundamento do conhecimento do tema investigado (Ferenhof \& Fernandes, 2016).

O processo de revisão da literatura requer a elaboração de uma síntese pautada em diferentes tópicos, capazes de criar uma ampla compreensão sobre o conhecimento. A revisão da literatura é um primeiro passo para a construção do conhecimento científico, pois é através desse processo que novas teorias surgem, bem como são reconhecidas lacunas e oportunidades para o surgimento de pesquisas num assunto específico (Botelho, Cunha, \& Macedo, 2011).

A revisão integrativa é uma ferramenta de investigação que permite à procura, a avaliação crítica e a síntese de evidências disponíveis sobre o tema investigado, em que o produto final é o estado do conhecimento, a implementação de intervenções efetivas na prestação de cuidados e na redução de custos. Além disso, permite a identificação de fragilidades, que poderão conduzir ao desenvolvimento de futuras investigações (Sousa, Marques-Vieira, Severino, \& Antunes, 2017).

A revisão integrativa permite que o leitor reconheça os profissionais que mais investigam determinado assunto, separar o achado científico de opiniões e ideias, além de descrever o conhecimento no seu estado atual, promovendo impacto 
sobre a prática clínica. Este método de pesquisa proporciona aos profissionais de saúde dados relevantes de um determinado assunto, em diferentes lugares e momentos, mantendo-os atualizados e facilitando as mudanças na prática clínica como consequência da pesquisa. Dessa forma, acredita-se que a revisão integrativa é uma ferramenta importante no processo de comunicação dos resultados de pesquisas, facilitando a utilização desses na prática clínica, uma vez que proporciona uma síntese do conhecimento já produzido e fornece subsídios para a melhoria da assistência à saúde (Mendes, Silveira, \& Galvão, 2008).

Figura 1. Fluxograma fases distintas da revisão integrativa.

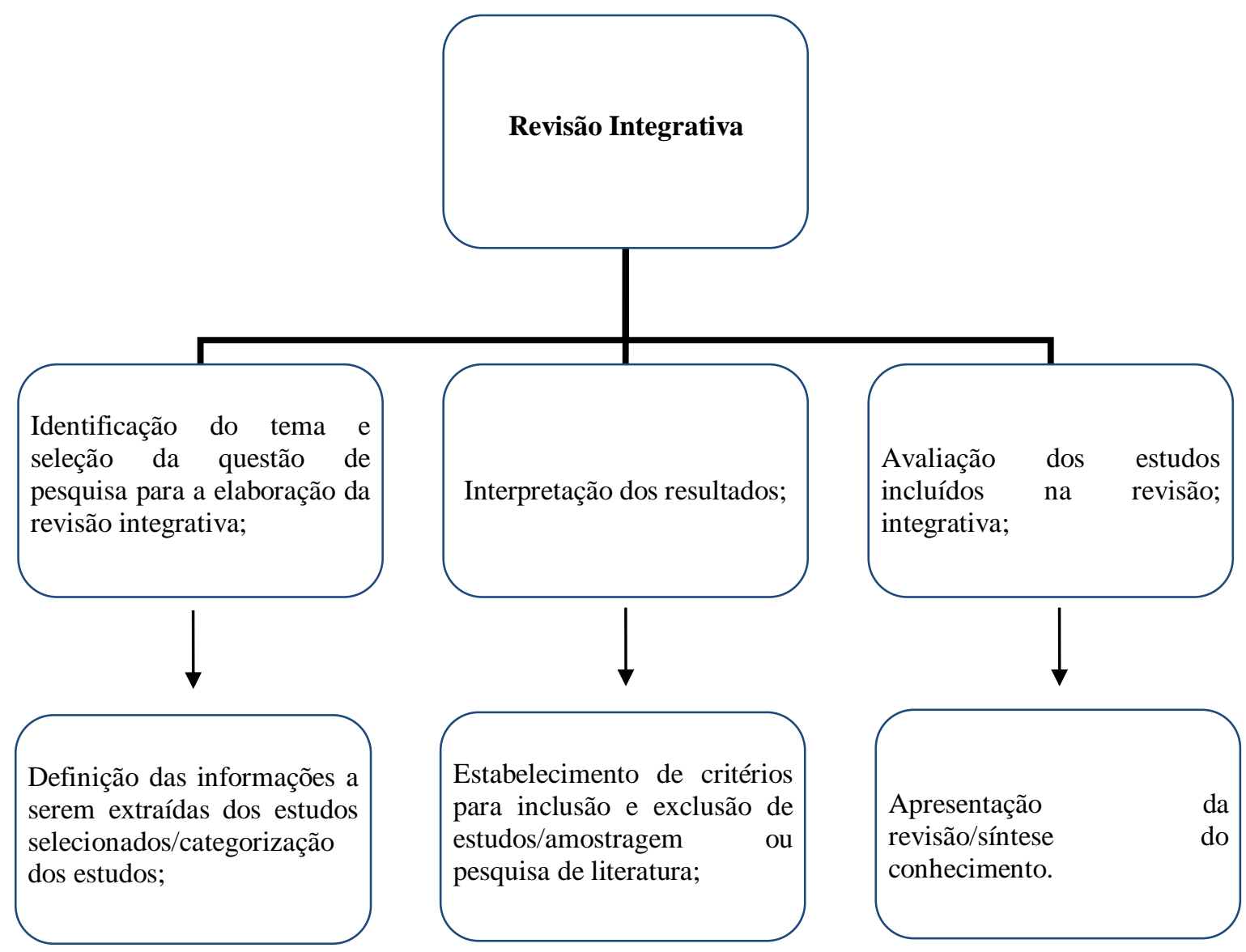

Fonte: Mendes, Silveira, \& Galvão (2008).

A revisão integrativa é um tipo de pesquisa que fornece informações mais amplas de maneira sistemática, ordenada e abrangente, sobre um assunto ou tema, com a finalidade de sintetizar resultados obtidos em pesquisa sobre temas ou questões. A definição das informações a serem extraídas dos estudos selecionados por categorização; avaliação dos estudos incluídos; interpretação dos resultados; e apresentação da revisão/síntese do conhecimento (Ercole, Melo, \& Alcoforado, 2015).

Estudo elaborado com abordagem qualitativa tornando-se importante a interpretação por parte do pesquisador com suas opiniões sobre o fenômeno em estudo. Neste tipo de pesquisa destacam-se algumas características como: a pesquisa qualitativa, em geral, ocorre no ambiente natural com coleta direta de dados e o pesquisador é o principal instrumento; os dados coletados são preferencialmente descritivos; a preocupação do processo é predominante em relação à do produto; a análise de dados e informações tende a seguir um processo indutivo (Pereira, Shitsuka, Parreira, \& Shitsuka, 2018). 
A pesquisa qualitativa envolve uma abordagem interpretativa do mundo, o que significa que seus pesquisadores estudam as coisas em seus cenários naturais, tentando entender os fenômenos em termos dos significados que as pessoas a eles conferem. A pesquisa qualitativa atribui importância fundamental aos depoimentos dos atores sociais envolvidos, aos discursos e aos significados transmitidos por eles. Nesse sentido, esse tipo de pesquisa preza pela descrição detalhada dos fenômenos e dos elementos que o envolvem (Augusto, Souza, Dellagnelo, \& Cario, 2014).

De acordo com Souza, Silva e Carvalho (2010), a ser realizada nas seguintes etapas: 1- Elaboração da pergunta norteadora; 2- Busca nas bases de dados e amostragem; 3- Coleta de dados, 4- Análise crítica.

Para responder à questão norteadora do estudo: "Quais as contribuições da assistência de enfermagem no acolhimento de adolescentes com ideações suicidas"? Aplicou-se os descritores/palavras-chaves: "Sepse", "Cateter Venoso central", "Unidade de Terapia Intensiva".

A busca efetuou-se, através da Plataforma da Biblioteca Virtual em Saúde - BVS, utilizando as bases de dados Literatura Latino-Americana e do Caribe em Ciências da Saúde (LILACS), Base de Dados de Enfermagem (BDENF), por meio da - Scientific Electronic Library Online (SCIELO). Aderindo-se através dos descritores/palavras chaves: "Sepse", "Cateter venoso central", "Unidade de Terapia Intensiva", combinados com o operador booleano "AND".

Os critérios de inclusão estabelecidos foram: artigos originais disponibilizados na íntegra, completos, que abrangessem a temática e na forma online, publicados nos idiomas português, inglês e espanhol, publicações que respondiam a questão norteadora do estudo. Os critérios de exclusão estabelecidos na seleção foram: artigos incompletos, artigos duplicados, teses, dissertações, monografias, manuais, e publicações que não estavam de acordo com a questão norteadora do estudo. No início da pesquisa obteve-se 11817 publicações, após a aplicação dos critérios de inclusão e exclusão totalizou-se parcialmente 574 artigos, depois de uma leitura mais precisa aderiu-se um total final de 20 publicações de acordo para serem trabalhadas na elaboração do referido estudo.

O fluxograma representado abaixo, caracteriza a estratégia de coleta de dados utilizada pelos autores, no sentido de detalhar as principais evidencias encontradas no estudo. 
Figura 2. Fluxograma Estratégia de Busca - Bases de Dados, Teresina-PI, Brasil, 2021.

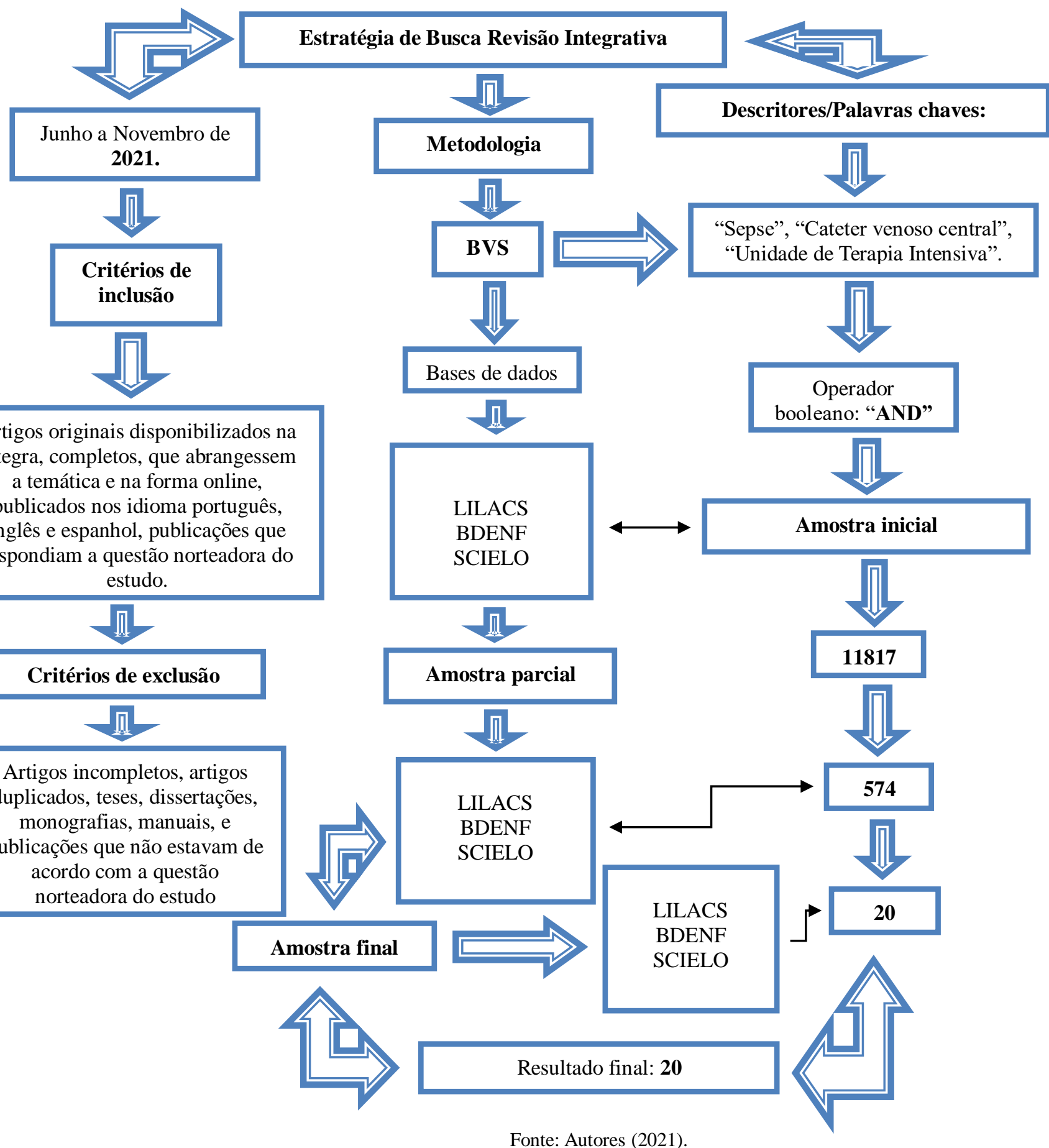

No Fluxograma 2, estão expostos a estratégia de busca, bases de dados, período de realização do estudo, critérios de inclusão e exclusão, amostra inicial, parcial e final, de acordo com a quantidade de artigos que irão compor os resultados do estudo.

O presente estudo assegura os aspectos éticos, garantindo a autoria dos artigos pesquisados, utilizando para as citações e referências dos autores as normas APA. Os preceitos éticos estabelecidos no que se refere a zelar pela legitimidade das informações, privacidade e sigilo das informações, quando necessárias, tornando os resultados desta pesquisa públicos. Os 
pesquisadores buscaram a legitimidade e fidelidade nas citações dos autores seja nas citações diretas ou parafraseadas no estudo.

\section{Resultados e Discussão}

Diante dos resultados obtidos no estudo por meio da estratégia de busca, os autores delinearam variáveis para melhor descrever as evidências encontradas na pesquisa. O quadro a seguir caracteriza os artigos com base nas variáveis propostas: número do artigo, base de dados, periódico, autor e ano de publicação, tipo de estudo, título, objetivo, resultados em evidências e conclusões importantes.

Quadro 1. Caracterização dos artigos selecionados para o estudo.

\begin{tabular}{|c|c|c|c|c|c|c|c|}
\hline $\mathbf{N}$ & $\begin{array}{l}\text { Base de } \\
\text { Dados }\end{array}$ & Periódico & $\begin{array}{l}\text { Autor e } \\
\text { Ano }\end{array}$ & $\begin{array}{l}\text { Tipo de } \\
\text { Estudo }\end{array}$ & Título & Objetivo & $\begin{array}{l}\text { Resultados em evidências e conclusões } \\
\text { importantes }\end{array}$ \\
\hline 1 & LILACS & $\begin{array}{l}\text { Rev Bras } \\
\text { Clin Med. }\end{array}$ & $\begin{array}{l}\text { Todeschi } \\
\text { ni, \& } \\
\text { Schuelter } \\
\text {-Trevisol, } \\
2011 .\end{array}$ & $\begin{array}{c}\text { Estudo } \\
\text { epidemiológic } \\
\text { o com } \\
\text { delineamento } \\
\text { transversal. }\end{array}$ & $\begin{array}{l}\text { Sepse associada } \\
\text { ao cateter venoso } \\
\text { central em } \\
\text { pacientes adultos } \\
\text { internados em } \\
\text { unidade de terapia } \\
\text { intensiva. }\end{array}$ & $\begin{array}{l}\text { Estabelecer o perfil } \\
\text { epidemiológico dos } \\
\text { casos de sepse em } \\
\text { pacientes adultos } \\
\text { internados na UTI em } \\
\text { um hospital escola no } \\
\text { Sul do Brasil. }\end{array}$ & $\begin{array}{l}\text { No período estudado houve } 83 \text { casos de } \\
\text { sepse associada ao cateter venoso central, } \\
\text { sendo que apenas } 49,4 \% \text { foram } \\
\text { confirmados laboratorialmente. O perfil } \\
\text { predominante era de homens adultos } \\
\text { jovens, e a principal causa de internação } \\
\text { foi o politraumatismo. Do total } 53 \% \\
\text { faleceram e a principal bactéria isolada foi } \\
\text { o Staphylococcus coagulase negativa } \\
(58,5 \%) \text {. }\end{array}$ \\
\hline 2 & SCIELO & $\begin{array}{l}\text { Cienc Cuid } \\
\text { Saúde. }\end{array}$ & $\begin{array}{l}\text { Freitas, } \\
\text { Picanço, } \\
\text { Assis, \& } \\
\text { Assis, } \\
2021 .\end{array}$ & $\begin{array}{l}\text { Estudo de } \\
\text { corte } \\
\text { transversal, de } \\
\text { abordagem } \\
\text { retrospectiva. }\end{array}$ & $\begin{array}{l}\text { Fatores associados } \\
\text { ao desenvolvi- } \\
\text { mento de sepse } \\
\text { em pacientes } \\
\text { internados em } \\
\text { terapia intensiva } \\
\text { cirúrgica. }\end{array}$ & \begin{tabular}{lr}
\multicolumn{3}{l}{ Verificar a associação } \\
entre os fatores de \\
risco e & o \\
desenvolvimento de \\
sepse em pacientes \\
cirúrgicos & ou \\
hemodinâmicos inter- \\
nados em & uma \\
unidade de & terapia \\
intensiva & (UTI) \\
cirúrgica.
\end{tabular} & $\begin{array}{l}\text { Com base nos resultados, houve uma } \\
\text { baixa prevalência de sepse na unidade } \\
\text { estudada, foi possível encontrar } \\
\text { associação entre o tempo de internamento } \\
\text { prolongado na UTI e o desenvolvimento } \\
\text { de sepse. Além disso, observou- se uma } \\
\text { maior probabilidade da ocorrência de } \\
\text { óbitos entre os pacientes que } \\
\text { desenvolveram sepse, quando comparados } \\
\text { aos que não desenvolveram, o que chama } \\
\text { atenção para a adoção de medidas } \\
\text { preventivas e terapêuticas para esse perfil } \\
\text { de pacientes. }\end{array}$ \\
\hline 3 & LILACS & $\begin{array}{c}\text { Rev Soc } \\
\text { Bras Med } \\
\text { Trop. }\end{array}$ & $\begin{array}{l}\text { Carvalho, } \\
\text { Vieira, } \\
\text { Filho, } \\
\text { \& Ribas, } \\
2010 .\end{array}$ & $\begin{array}{l}\text { Estudo } \\
\text { prospectivo. }\end{array}$ & $\begin{array}{l}\text { Sepse, sepse grave } \\
\text { e choque séptico: } \\
\text { aspectos clínicos, } \\
\text { epidemiológicos e } \\
\text { prognóstico em } \\
\text { pacientes de } \\
\text { Unidade de } \\
\text { Terapia Intensiva } \\
\text { de um Hospital } \\
\text { Universitário. }\end{array}$ & $\begin{array}{l}\text { Determinar as taxas } \\
\text { de incidência de } \\
\text { sepse, sepse grave e } \\
\text { choque séptico, de } \\
\text { natureza comunitária } \\
\text { e hospitalar, primária } \\
\text { e secundária com e } \\
\text { sem critérios } \\
\text { microbiológicos bem } \\
\text { como sua evolução. }\end{array}$ & $\begin{array}{l}\text { As infecções sanguíneas são classificadas } \\
\text { em primárias e secundárias, baseada na } \\
\text { ausência ou presença de foco de infecção } \\
\text { conhecido fora do sistema vascular. O } \\
\text { principal foco nas infecções secundárias é } \\
\text { o pulmão, respondendo por } 50 \% \text { de todos } \\
\text { os casos. A sepse primária é usualmente } \\
\text { (85\%) relacionada com o cateter venoso } \\
\text { central (CVC) e, apresenta uma taxa de } \\
\text { mortalidade entre } 12 \% \text { e } 25 \% \text {, } \\
\text { aumentando o tempo de hospitalização do } \\
\text { paciente de } 10 \text { para } 40 \text { dias. }\end{array}$ \\
\hline 4 & BDENF & $\begin{array}{l}\text { Arq. } \\
\text { Catarin } \\
\text { Med. }\end{array}$ & $\begin{array}{l}\text { Reiner, } \\
\text { Vietta, } \\
\text { Vignardi, } \\
\text { Gama, \& } \\
\text { Klingelfu } \\
\text { s, } 2020 .\end{array}$ & $\begin{array}{l}\text { Estudo } \\
\text { transversal } \\
\text { analítico. }\end{array}$ & $\begin{array}{l}\text { Desfecho clínico e } \\
\text { fatores associados } \\
\text { ao óbito em } \\
\text { pacientes com } \\
\text { sepse internados } \\
\text { em unidade de } \\
\text { terapia intensiva. }\end{array}$ & $\begin{array}{l}\text { Conhecer o desfecho } \\
\text { clínico e os fatores } \\
\text { associados ao óbito } \\
\text { em pacientes com } \\
\text { sepse internados na } \\
\text { Unidade de Terapia } \\
\text { Intensiva. }\end{array}$ & $\begin{array}{l}\text { Encontra-se importante prevalência e } \\
\text { mortalidade associada à sepse. O risco de } \\
\text { mortalidade associado à sepse tem } \\
\text { influência direta das condições clínicas do } \\
\text { paciente, das comorbidades associadas, do } \\
\text { sítio de infecção, da sensibilidade dos } \\
\text { microrganismos aos antimicrobianos, bem } \\
\text { como da variedade e quantidade de } \\
\text { procedimentos invasivos realizados, } \\
\text { rotineiramente. }\end{array}$ \\
\hline
\end{tabular}




\begin{tabular}{|c|c|c|c|c|c|c|c|}
\hline 5 & SCIELO & $\begin{array}{l}\text { Cad. Saúde } \\
\text { Colet. }\end{array}$ & $\begin{array}{l}\text { Barros, } \\
\text { Maia, \& } \\
\text { Monteiro } \\
\text {,2016. }\end{array}$ & $\begin{array}{l}\text { Estudo } \\
\text { retrospectivo, } \\
\text { descritivo, } \\
\text { observacional. }\end{array}$ & $\begin{array}{lr}\text { Fatores de } & \text { risco } \\
\text { associados } & \text { ao } \\
\text { agravamento } & \text { de } \\
\text { sepse } & \text { em } \\
\text { pacientes } & \text { em } \\
\text { Unidade } & \text { de } \\
\text { Terapia Intensiva. }\end{array}$ & 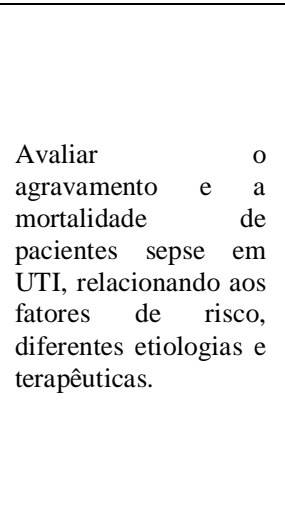 & $\begin{array}{l}\text { Evidencia-se que a maioria dos pacientes } \\
\text { com sepse internados no UTI desenvolveu } \\
\text { choque séptico, que ocasionou maior } \\
\text { número de óbitos destes pacientes. Os } \\
\text { principais fatores de risco que estão } \\
\text { associados ao agravamento desta } \\
\text { patologia foram: idade superior que } 65 \\
\text { anos, maior tempo médio de internação na } \\
\text { UTI, elevada frequência de comorbidades } \\
\text { (DM, Neoplasias e HAS) e a utilização de } \\
\text { procedimentos invasivos. As bactérias } \\
\text { foram os micro-organismos mais } \\
\text { frequentemente isolados, principalmente } \\
\text { bacilos gram-negativos e cocos gram- } \\
\text { positivos que apresentaram perfil de } \\
\text { multirresistência. }\end{array}$ \\
\hline 6 & SCIELO & $\begin{array}{l}\text { Cogitare } \\
\text { Enferm. }\end{array}$ & $\begin{array}{l}\text { Neto, } \\
\text { Campos, } \\
\text { Marques, } \\
\text { Ramalho, } \\
\quad \& \\
\text { Nóbrega, } \\
2016 .\end{array}$ & $\begin{array}{l}\text { Estudo } \\
\text { exploratório, } \\
\text { de natureza } \\
\text { qualitativa. }\end{array}$ & $\begin{array}{lr}\text { Concepções } & \text { de } \\
\text { enfermeiros } & \text { que } \\
\text { atuam em unidade } & \text { de } \\
\text { derapia } \\
\text { intensiva } & \text { geral } \\
\text { sobre sepse. }\end{array}$ & $\begin{array}{lr}\text { Verificar } & \mathrm{o} \\
\text { entendimento } & \text { de } \\
\text { enfermeiros de uma } \\
\text { Unidade de Terapia } \\
\text { Intensiva Geral em } \\
\text { relação à sepse. }\end{array}$ & $\begin{array}{l}\text { A tarefa de cuidar do paciente gravemente } \\
\text { enfermo na UTI exige conhecimento de } \\
\text { enfermagem especializado, devido às } \\
\text { diferentes e complexas demandas de } \\
\text { atenção, necessárias para identificar tanto } \\
\text { os sinais de sepse quanto os potenciais } \\
\text { indícios de deterioração clínica do } \\
\text { paciente séptico. }\end{array}$ \\
\hline 7 & BDENF & $\begin{array}{l}\text { Id On Line } \\
\text { Rev. Mult. } \\
\text { Psic. }\end{array}$ & $\begin{array}{l}\text { Aguiar, } \\
\text { Cruz, } \\
\text { Silva, } \\
\text { Sousa, \& } \\
\text { Moraes, } \\
2020 .\end{array}$ & $\begin{array}{l}\text { Estudo } \\
\text { qualitativo de } \\
\text { abordagem } \\
\text { descritiva. }\end{array}$ & $\begin{array}{l}\text { Sepse em Unidade } \\
\text { de } \quad \text { Terapia } \\
\text { Intensiva: fatores } \\
\text { predisponentes e a } \\
\text { atuação preventi- } \\
\text { va do enfermeiro. }\end{array}$ & $\begin{array}{l}\text { Compreende } r \\
\text { descrever os fatores } \\
\text { de risco da sepse e } \\
\text { descrever como o } \\
\text { enfermeiro atua na } \\
\text { sua prevenção na } \\
\text { Unidade de Terapia } \\
\text { Intensiva (UTI). }\end{array}$ & $\begin{array}{l}\text { O enfermeiro atuante na UTI adulto deve } \\
\text { manter-se capacitado e atualizado quanto } \\
\text { às evidências cientificas sobre sepse, } \\
\text { buscando também treinar e capacitar à } \\
\text { equipe, visto que esses profissionais têm } \\
\text { papel muito importante na propagação de } \\
\text { conhecimento e educação permanente, } \\
\text { pois ele planeja e coordena as ações de } \\
\text { enfermagem apoiado no conhecimento } \\
\text { técnico científico. }\end{array}$ \\
\hline 8 & SCIELO & $\begin{array}{l}\text { Revista } \\
\text { Eletrônica } \\
\text { Acervo } \\
\text { Saúde / } \\
\text { Electronic } \\
\text { Journal } \\
\text { Collection } \\
\text { Health. }\end{array}$ & $\begin{array}{l}\text { Filho, } \\
\text { Marinho, } \\
\& \text { Santos, } \\
2019 .\end{array}$ & $\begin{array}{c}\text { Estudo } \\
\text { qualitativo. }\end{array}$ & $\begin{array}{l}\text { Fatores de risco } \\
\text { em pacientes com } \\
\text { sepse em unidades } \\
\text { de rerapia } \\
\text { intensiva. }\end{array}$ & $\begin{array}{l}\text { Analisar os fatores de } \\
\text { risco em pacientes } \\
\text { com sepse em } \\
\text { unidades de terapia } \\
\text { intensiva. }\end{array}$ & $\begin{array}{l}\text { É possível afirmar que os bons resultados } \\
\text { em relação à sepse, devem-se pelo fato do } \\
\text { diagnóstico precoce, com o pronto } \\
\text { atendimento nas unidades de terapia } \\
\text { intensiva, aliado ao tratamento iniciado } \\
\text { nas primeiras horas após a identificação } \\
\text { da doença. Desse modo, o diagnóstico } \\
\text { precoce promove a identificação do foco } \\
\text { infeccioso, do agente patogênico, bem } \\
\text { como a utilização da terapêutica } \\
\text { adequada. }\end{array}$ \\
\hline 9 & SCIELO & $\begin{array}{l}\text { Braz. J. Of } \\
\text { Develop. }\end{array}$ & $\begin{array}{l}\text { Martins, } \\
\text { Sandim, } \\
\text { Felipe, \& } \\
\text { Sousa, } \\
2020 .\end{array}$ & $\begin{array}{c}\text { Estudo } \\
\text { qualitativo } \\
\text { exploratório. }\end{array}$ & 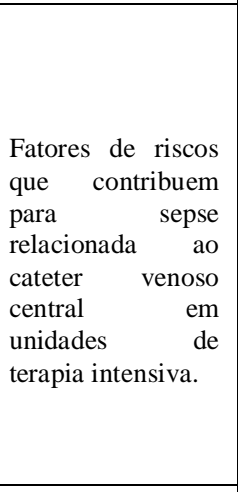 & $\begin{array}{l}\text { Identificar os } \\
\text { principais fatores de } \\
\text { risco que contribuem } \\
\text { para que ocorra sepse } \\
\text { relacionada ao CVC } \\
\text { em UTI's. }\end{array}$ & $\begin{array}{l}\text { Uma equipe qualificada e bem treinada } \\
\text { para manutenção e remoção dos CVC } \\
\text { melhoram as taxas de ICS e diminuem os } \\
\text { custos associados, pois havendo } \\
\text { capacitação não ocorre contaminação por } \\
\text { quebra da técnica asséptica, até mesmo } \\
\text { pelos hubs de inserção durante o manejo e } \\
\text { fluidos administrados, devendo estes ser } \\
\text { limpos por álcool } 70 \% \text { conforme } \\
\text { protocolo antes da infusão de fluidos, } \\
\text { acredita-se que o risco de infecção está na } \\
\text { permanência do dispositivo com tempo } \\
\text { maior que } 14 \text { dias, sendo as vias que } \\
\text { deverão ser evitadas pela equipe, a jugular } \\
\text { e femoral. }\end{array}$ \\
\hline $\begin{array}{l}1 \\
0\end{array}$ & SCIELO & $\begin{array}{l}\text { ReBIS - } \\
\text { Revista } \\
\text { Brasileira } \\
\text { Interdiscipli } \\
\text { nar de } \\
\text { Saúde. }\end{array}$ & $\begin{array}{l}\text { Neto, } \\
\text { Dias, } \\
\text { Ribeiro, } \\
\text { \& Lima, } \\
2020 .\end{array}$ & $\begin{array}{c}\text { Estudo } \\
\text { qualitativo. }\end{array}$ & $\begin{array}{lr}\text { Prevenção } & \text { e } \\
\text { controle de } & \text { de } \\
\text { infecções: cateter } \\
\text { venoso central em } \\
\text { unidade de terapia } \\
\text { intensiva adulto. }\end{array}$ & $\begin{array}{l}\text { Discutir as medidas } \\
\text { de prevenção e } \\
\text { controle adotadas por } \\
\text { profissionais de saúde } \\
\text { nesse cenário, } \\
\text { sobretudo ra } \\
\text { enfermagem. }\end{array}$ & $\begin{array}{l}\text { Portanto, os principais fatores } \\
\text { relacionados a infecção de corrente } \\
\text { sanguínea por uso de CVC estão } \\
\text { associados a falhas em protocolos de } \\
\text { segurança do paciente. Contudo, os } \\
\text { profissionais de enfermagem, com } \\
\text { destaque para atuação do enfermeiro, são } \\
\text { responsáveis por evitar/minimizar essas } \\
\text { infeç̧ões no contexto das UTIs adulto, } \\
\text { mediante intervenções respaldadas em } \\
\text { recomendações dos órgãos competentes, } \\
\text { como a ANVISA. }\end{array}$ \\
\hline
\end{tabular}




\begin{tabular}{|c|c|c|c|c|c|c|c|}
\hline $\begin{array}{l}1 \\
1\end{array}$ & SCIELO & $\begin{array}{c}\text { Revista } \\
\text { Enfermage } \\
\text { m em } \\
\text { Evidência. }\end{array}$ & $\begin{array}{c}\text { Borges, } \\
\text { Souza, \& } \\
\text { Spolidoro } \\
\text {,2018. }\end{array}$ & $\begin{array}{c}\text { Estudo } \\
\text { qualitativo. }\end{array}$ & $\begin{array}{lr}\text { Atuação } & \text { do } \\
\text { enfermeiro } & \text { frente } \\
\text { ao risco } & \text { de } \\
\text { infecção } & \text { com } \\
\text { cateter } & \text { venoso } \\
\text { central na unidade } \\
\text { de } & \text { terapia } \\
\text { intensiva. } & \end{array}$ & $\begin{array}{l}\text { Identificar quais as } \\
\text { medidas preventivas e } \\
\text { de controle de } \\
\text { infecção relacionada } \\
\text { ao uso de cateter } \\
\text { venoso central em } \\
\text { UTI, e, identificar as } \\
\text { causas, os tipos e os } \\
\text { fatores de risco para } \\
\text { essa infecção. }\end{array}$ & $\begin{array}{l}\text { Portanto evidencia-se que a enfermagem } \\
\text { tem papel fundamental na redução das } \\
\text { taxas deste tipo de infecção, contribuindo } \\
\text { assim, para segurança do paciente e para } \\
\text { uma assistência de qualidade. }\end{array}$ \\
\hline $\begin{array}{l}1 \\
2\end{array}$ & SCIELO & $\begin{array}{l}\text { Rev. Adm. } \\
\text { Saúde. }\end{array}$ & $\begin{array}{l}\text { Sousa, } \\
\text { Pereira, } \\
\text { Rezende, } \\
\text { Laura, } \\
2018 .\end{array}$ & $\begin{array}{l}\text { Estudo do tipo } \\
\text { auditoria } \\
\text { clínica. }\end{array}$ & $\begin{array}{l}\text { Avaliação dos } \\
\text { cuidados de } \\
\text { enfermagem com } \\
\text { o cateter venoso } \\
\text { central em uma } \\
\text { unidade de terapia } \\
\text { intensiva adulto e } \\
\text { pediátrica. }\end{array}$ & $\begin{array}{l}\text { avaliar os cuidados de } \\
\text { enfermagem } \\
\text { relacionados ao } \\
\text { cateter venoso } \\
\text { central (CVC) em } \\
\text { uma Unidade de } \\
\text { Terapia Intensiva } \\
\text { adulto e pediátrica. }\end{array}$ & $\begin{array}{l}\text { A auditoria no cuidado de enfermagem na } \\
\text { troca de curativo de CVC favorece um } \\
\text { processo educativo entre os enfermeiros, } \\
\text { no qual não se buscou os responsáveis } \\
\text { pela falha, mas questionou-se o porquê da } \\
\text { não conformidade. Além disso, contribuiu } \\
\text { para identificar estratégias para melhorar } \\
\text { a assistência de enfermagem, no intuito de } \\
\text { oferecer um cuidado seguro e de } \\
\text { qualidade. }\end{array}$ \\
\hline $\begin{array}{l}1 \\
3\end{array}$ & SCIELO & $\begin{array}{c}\text { Brazilian } \\
\text { Journal Of } \\
\text { Health } \\
\text { Review. }\end{array}$ & $\begin{array}{c}\text { Faria et } \\
\text { al., } 2021 .\end{array}$ & $\begin{array}{l}\text { Estudo } \\
\text { documental, } \\
\text { retrospectiva, } \\
\text { de abordagem } \\
\text { quantitativa. }\end{array}$ & $\begin{array}{l}\text { Infecção de } \\
\text { corrente sanguínea } \\
\text { relacionada a a } \\
\text { cateter venoso } \\
\text { central: avaliação } \\
\text { dos fatores de } \\
\text { riscos. }\end{array}$ & $\begin{array}{l}\text { Identificar fatores de } \\
\text { riscos associados ao } \\
\text { desenvolvimento de } \\
\text { infecção de corrente } \\
\text { sanguínea relacionada } \\
\text { a cateter venoso } \\
\text { central em pacientes } \\
\text { internados em } \\
\text { Unidade de Terapia } \\
\text { Intensiva de um } \\
\text { hospital em Belo } \\
\text { Horizonte, Minas } \\
\text { Gerais, Brasil. }\end{array}$ & $\begin{array}{l}\text { Evidencia-se que é possível minimizar a } \\
\text { ocorrência das infecções de corrente } \\
\text { sanguínea relacionada a cateter venoso } \\
\text { central através de práticas adequadas, } \\
\text { tanto no âmbito gerencial quanto } \\
\text { assistencial, assim como por meio de } \\
\text { capacitações que visam conscientizar, } \\
\text { informar e sensibilizar os profissionais } \\
\text { envolvidos na assistência. }\end{array}$ \\
\hline $\begin{array}{l}1 \\
4\end{array}$ & BDENF & $\begin{array}{c}\text { Facene/Fa } \\
\text { mene. }\end{array}$ & $\begin{array}{l}\text { Neto, } \\
\text { Barros, } \\
\text { Oliveira, } \\
\text { Fontes, \& } \\
\text { Nóbrega, } \\
2011 .\end{array}$ & $\begin{array}{l}\text { Estudo de } \\
\text { campo. }\end{array}$ & $\begin{array}{l}\text { Assistência de } \\
\text { enfermagem a } \\
\text { pacientes sépticos } \\
\text { em uma unidade } \\
\text { de terapia } \\
\text { intensiva adulto. }\end{array}$ & $\begin{array}{lr}\text { Identificar } & \text { os } \\
\text { principais } & \\
\text { diagnósticos } & \text { de } \\
\text { enfermagem } & \text { em } \\
\text { adultos sépticos } & \\
\text { hospitalizados } & \text { em } \\
\text { uma Unidade } & \text { de } \\
\text { Terapia Intensiva da } \\
\text { cidade de João } \\
\begin{array}{ll}\text { Pessoa-PB. } \\
\end{array}\end{array}$ & $\begin{array}{l}\text { O estudo tem relevância no sentido de } \\
\text { divulgar a importância da SAE e mostrar } \\
\text { a sua imperatividade na qualidade do } \\
\text { cuidado, como também ele aponta para a } \\
\text { possibilidade que os enfermeiros } \\
\text { envolvidos no cuidar desses pacientes } \\
\text { críticos têm de utilizar esses diagnósticos } \\
\text { identificados como referência para } \\
\text { discussão, favorecendo a universalização } \\
\text { da nossa linguagem científica e a } \\
\text { sistematização do cuidado. }\end{array}$ \\
\hline $\begin{array}{l}1 \\
5\end{array}$ & SCIELO & $\begin{array}{l}\text { Rev. } \\
\text { Investig. } \\
\text { Bioméd. }\end{array}$ & $\begin{array}{l}\text { Rodrigue } \\
\text { s, \& } \\
\text { Pereira, } \\
2016 .\end{array}$ & $\begin{array}{c}\text { Estudo } \\
\text { descritivo, } \\
\text { analítico e } \\
\text { transversal. }\end{array}$ & $\begin{array}{l}\text { Infecções relacio- } \\
\text { nadas à assistência } \\
\text { à saúde ocorridas } \\
\text { em uma Unidade } \\
\text { de } \\
\text { Intensivar. Terapia }\end{array}$ & $\begin{array}{l}\text { Descrever a } \\
\text { ocorrência de infecção } \\
\text { relacionada à } \\
\text { assistência à saúde na } \\
\text { UTI de um hospital } \\
\text { público de alta } \\
\text { complexidade e } \\
\text { referência para ensino } \\
\text { em São Luís - MA. }\end{array}$ & $\begin{array}{l}\text { A sepse é uma causa importante de } \\
\text { hospitalização, e a principal causa de } \\
\text { morte em UTI, trata-se de uma síndrome } \\
\text { de resposta inflamatória, motivada por um } \\
\text { agente agressor, associada à infecção } \\
\text { sistêmica. Os sinais e sintomas } \\
\text { apresentam de forma diversificada, } \\
\text { sobretudo em pacientes graves, cujas } \\
\text { doenças são complexas e com frequência } \\
\text { já estão em uso de antimicrobianos. }\end{array}$ \\
\hline $\begin{array}{l}1 \\
6\end{array}$ & SCIELO & $\begin{array}{l}\text { Uaemex. } \\
\text { mx. }\end{array}$ & $\begin{array}{c}\text { Jesus, } \\
\text { Alves, \& } \\
\text { Valente, } \\
2013 .\end{array}$ & $\begin{array}{l}\text { Estudo } \\
\text { quantitativo, } \\
\text { descritivo e } \\
\text { transversal. }\end{array}$ & $\begin{array}{lr}\text { Prevenção } & \text { e } \\
\text { controle } & \text { de } \\
\text { infecção relacio } & - \\
\text { nada a } & \text { cateter } \\
\text { venoso } & \text { central } \\
\text { uma } & \text { revisão } \\
\text { integrativa } & \text { da } \\
\text { literatura. } & \end{array}$ & $\begin{array}{lr}\text { Identificar } & \text { a } \\
\text { percepção } & \text { das } \\
\text { enfermeiras em } & \text { em } \\
\text { relação com a cultura } \\
\text { de segurança na } \\
\text { atenção da saúde do } \\
\text { usuário. }\end{array}$ & $\begin{array}{l}\text { Prevenir e controlar as infecções } \\
\text { relacionadas ao acesso vascular, é } \\
\text { primordial no cuidado ao paciente crítico, } \\
\text { e a enfermagem tem um papel essencial } \\
\text { nessa prevenção e cuidado, pois esta } \\
\text { categoria profissional é responsável } \\
\text { corrente sanguínea, perpassam na criação } \\
\text { de protocolos e padronização das técnicas, } \\
\text { mas também na atualização e } \\
\text { aperfeiçoamento constante dos } \\
\text { enfermeiros e aplicação da sistematização } \\
\text { do cuidado de enfermagem, para que a } \\
\text { construção e manutenção desse } \\
\text { conhecimento permitam ao profissional } \\
\text { enfermeiro definir diretrizes para a prática } \\
\text { clínica e melhorar a qualidade da } \\
\text { assistência prestada ao cliente. }\end{array}$ \\
\hline
\end{tabular}




\begin{tabular}{|c|c|c|c|c|c|c|c|}
\hline $\begin{array}{l}1 \\
7\end{array}$ & SCIELO & $\begin{array}{c}\text { Herrero.co } \\
\text { m.br. }\end{array}$ & $\begin{array}{c}\text { Sossai, \& } \\
\text { Almeida, } \\
2011 .\end{array}$ & $\begin{array}{c}\text { Estudo } \\
\text { qualitativo. }\end{array}$ & $\begin{array}{l}\text { Infecção hospita- } \\
\text { lar na unidade de } \\
\text { terapia intensiva: } \\
\text { fatores de risco e } \\
\text { mortalidade. }\end{array}$ & $\begin{array}{l}\text { Conhecer os fatores } \\
\text { de risco e meios de } \\
\text { contaminação presen- } \\
\text { tes numa unidade de } \\
\text { terapia intensiva, } \\
\text { assim como avaliar a } \\
\text { relação existente entre } \\
\text { infecção } \\
\text { mortalidade } \\
\text { pacientes. }\end{array}$ & $\begin{array}{l}\text { As infecções hospitalares são as principais } \\
\text { causas de morte nas unidades de terapia } \\
\text { intensiva, representando uma ampliação } \\
\text { no tempo de internação, além de um custo } \\
\text { elevado para as instituições, por agregar } \\
\text { inúmeros fatores de risco como: } \\
\text { condições clínicas desfavoráveis, } \\
\text { comorbidades, uso de técnicas invasivas e } \\
\text { alterações na microbiota. A assistência } \\
\text { aos pacientes críticos requer a inevitável } \\
\text { aplicação de procedimentos invasivos e a } \\
\text { administração de antimicrobianos de } \\
\text { amplo espectro, sendo importante assim a } \\
\text { redobrada atenção de todos os } \\
\text { profissionais envolvidos quanto ao uso de } \\
\text { técnicas cada vez mais assépticas, a } \\
\text { lavagem rotineira das mãos e o uso } \\
\text { controlado e estritamente necessário de } \\
\text { técnicas invasivas e de antibióticos na } \\
\text { rotina dos cuidados. }\end{array}$ \\
\hline $\begin{array}{l}1 \\
8\end{array}$ & SCIELO & $\begin{array}{c}\text { Vigil. } \\
\text { Sanit. } \\
\text { Debate. }\end{array}$ & $\begin{array}{c}\text { Silva, \& } \\
\text { Oliveira, } \\
2016 .\end{array}$ & $\begin{array}{c}\text { Estudo } \\
\text { qualitativo. }\end{array}$ & $\begin{array}{lr}\text { Prevenção } & \text { da } \\
\text { infecção } & \text { da } \\
\text { corrente sanguínea } \\
\text { relacionada ao } \\
\text { cateter venoso } \\
\text { central. }\end{array}$ & $\begin{array}{l}\text { Analisar sobre a } \\
\text { adoção aos bundles } \\
\text { para prevenção de } \\
\text { infecção da corrente } \\
\text { sanguínea relacionada } \\
\text { ao cateter venoso } \\
\text { central em Unidade de } \\
\text { Terapia Intensiva. } \\
\end{array}$ & $\begin{array}{l}\text { Percebe-se que os bundles têm sido } \\
\text { amplamente divulgados e muitas vezes } \\
\text { estão sendo implementadas nas } \\
\text { instituições hospitalares como estratégias } \\
\text { para redução das infecções da corrente } \\
\text { sanguínea relacionadas ao CVC e sua } \\
\text { adoção tem reduzido de forma } \\
\text { significativa estas infecções. }\end{array}$ \\
\hline $\begin{array}{l}1 \\
9\end{array}$ & SCIELO & $\begin{array}{l}\text { Rev Bras } \\
\text { Enferm. }\end{array}$ & $\begin{array}{l}\text { Pedrosa, } \\
\text { Oliveira, } \\
\quad \& \\
\text { Machado } \\
\text {,2018. }\end{array}$ & $\begin{array}{c}\text { Estudo de } \\
\text { validação } \\
\text { metodológica } \\
\text { de } \\
\text { instrumento. }\end{array}$ & $\begin{array}{lr}\text { Validação } & \text { de } \\
\text { protocolo assisten- } \\
\text { cial ao paciente } \\
\text { séptico } \\
\text { Unidade } \\
\text { Terapia Intensiva. }\end{array}$ & 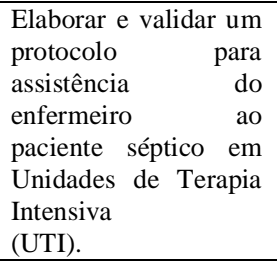 & $\begin{array}{l}\text { A partir da validação de conteúdo por } \\
\text { avaliadores/juízes, construiu-se um } \\
\text { protocolo com quinze itens referentes à } \\
\text { assistência do enfermeiro ao paciente } \\
\text { séptico em UTI, no intuito de nortear os } \\
\text { profissionais de saúde a assistir estes } \\
\text { pacientes em tempo hábil, de forma } \\
\text { efetiva e com qualidade. }\end{array}$ \\
\hline
\end{tabular}

Fonte: Autores (2021).

No Quadro 1, tem-se a apresentação dos artigos selecionados para o estudo conforme número do artigo, base de dados, periódico, autor e ano de publicação, tipo de estudo, título, objetivo, resultados em evidências e conclusões importantes, com a finalidade de facilitar o desenvolvimento da discussão. A partir do estudo dos artigos estabeleceram-se discussões relevantes para observações das produções científicas relacionadas à pesquisa.

No Gráfico 1, a seguir, estão expostos os periódicos e a quantidade de artigos encontrados na seleção da amostra final dos artigos que são trabalhados na elaboração do referido estudo. 
Gráfico 1. Distribuição dos artigos conforme periódico e quantidade e quantidade de artigos.

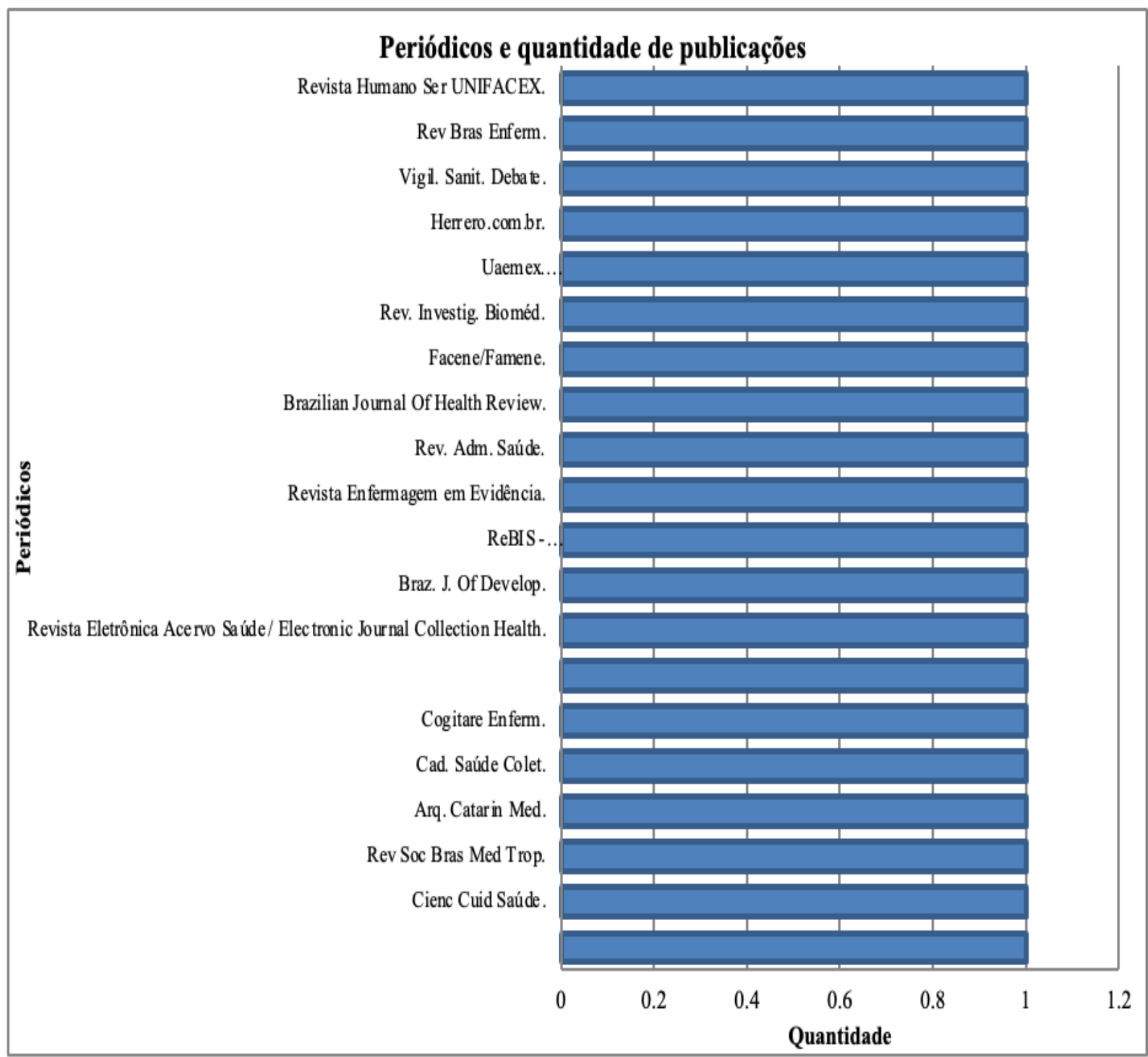

Fonte: Autores (2021).

Segundo o Gráfico ilustrado acima, pode-se observar os periódicos e a quantidade de artigos que foram publicados de acordo com a amostra final do referido estudo. Dessa forma, verifica-se que na Revista Humana Ser UNIFACEX ocorreu (1) Publicação, Rer Bras Enfer (1), Vigil Sanit Debate (1), Herrero.com.br (1), Vaemex.mx (1), Rer Ivestig Biomed (1), Faceme/Facene (1), Brazilian Journal Of Heath Review (1), Rer Adm Saúde (10), Revista Enfermagem em Evidências (1), ReBIS - Revista Brasileira Interdisciplinar de Saúde (1), Brazilian J Of Develop (1), Revista Eletrônica Acervo Saúde (1), Id Online Rer Mult Psic (1), Cogitare Enferm (1), Cad Saúde Colet (1), Arq Catarin Med (1), Rer Soc Bras Med Trop (1), Ciência Cuid Saúde (1), Rer Bras Clin Med (1). Assim, totalizando 20 artigos para serem trabalhados na elaboração do presente estudo.

De acordo, com o gráfico ilustrado acima, pode-se observar os periódicos e a porcentagem de artigos que foram publicados de acordo com a amostra final do referente estudo. Dessa forma, verifica-se que. Assim, totalizando 20 artigos para serem trabalhados na elaboração do presente estudo. 
Gráfico 2. Distribuição dos artigos conforme os anos de publicação e quantidade.

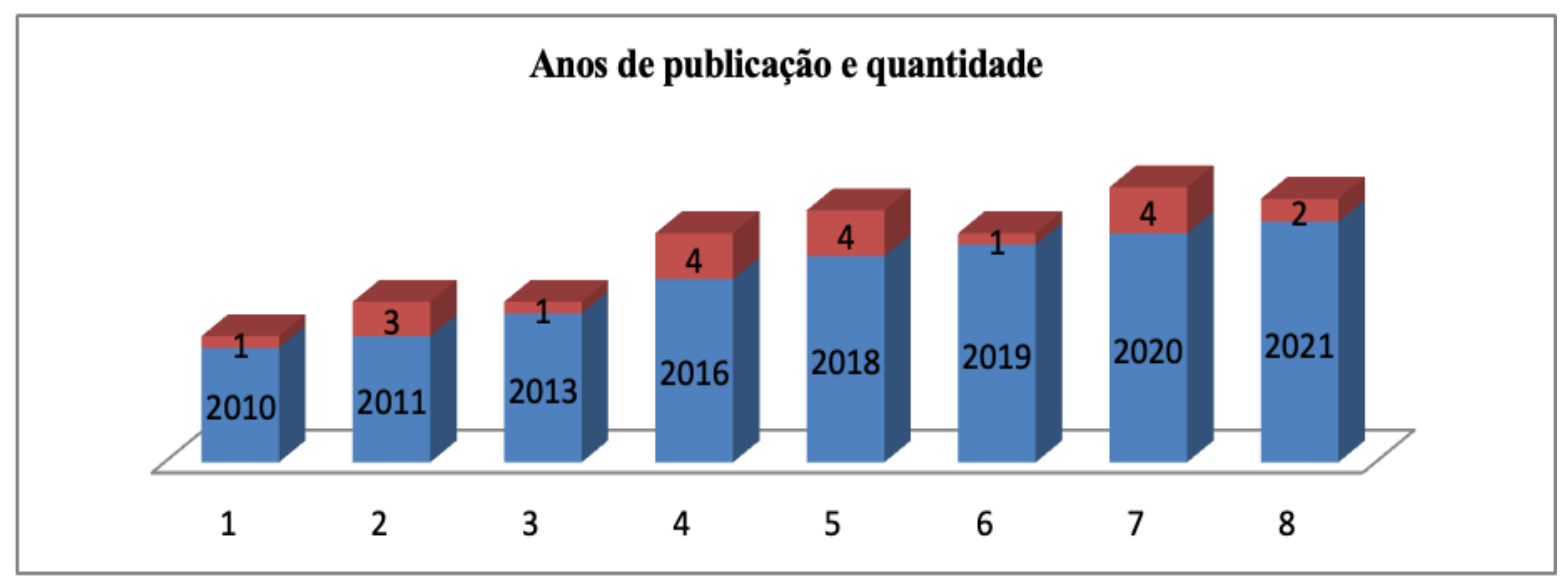

Fonte: Autores (2021).

Ao analisar o Gráfico representado acima, observa-se os anos de publicação e a quantidade de artigos publicados, nota-se que no ano de 2010 ocorreu (1) publicação, 2011 (3), 2013 (1), 2016 (4), 2018 (4), 2019 (1), 2020 (4), 2021 (2). Assim, totalizando 20 artigos publicados e selecionados para serem utilizados na elaboração do presente estudo.

Gráfico 3. Distribuição dos anos de publicação e porcetagem.

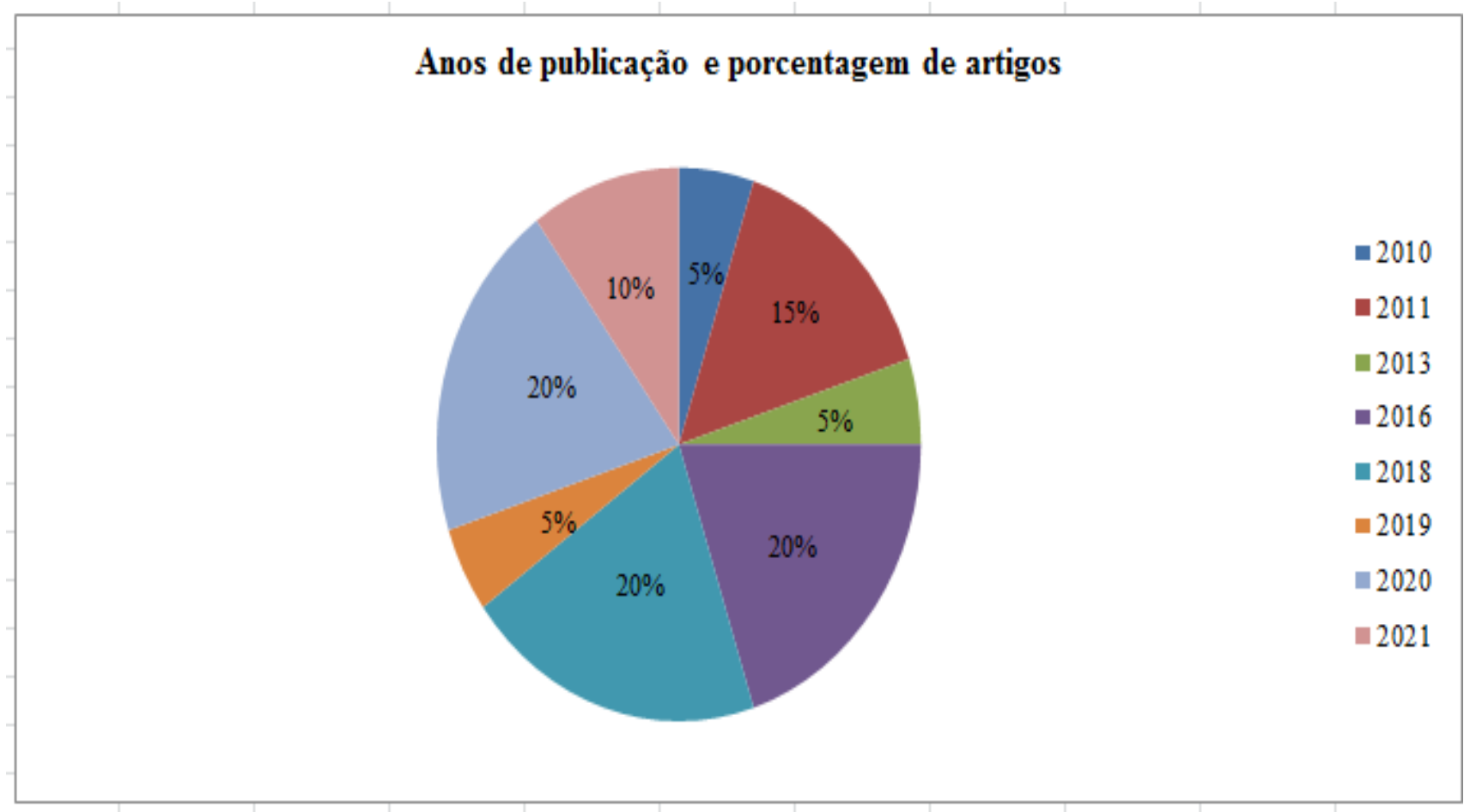

Fonte: Autores (2021).

Ao verificar o gráfico acima, percebe-se os anos de publicação e porcentagem dos artigos publicados de acordo com cada ano, identifica-se que no ano de 2010 ocorreu (5\%)2011 (15\%), 2013 (5\%), 2016 (20\%), 2018 (2020\%), 2019 (5\%), 2020 (20\%),2021 (10\%). totalizando 100\% das publicações, escolhidas para compor a construção do referido estudo. 
Gráfico 4. Distribuição dos artigos conforme os tipos de estudo e quantidade.

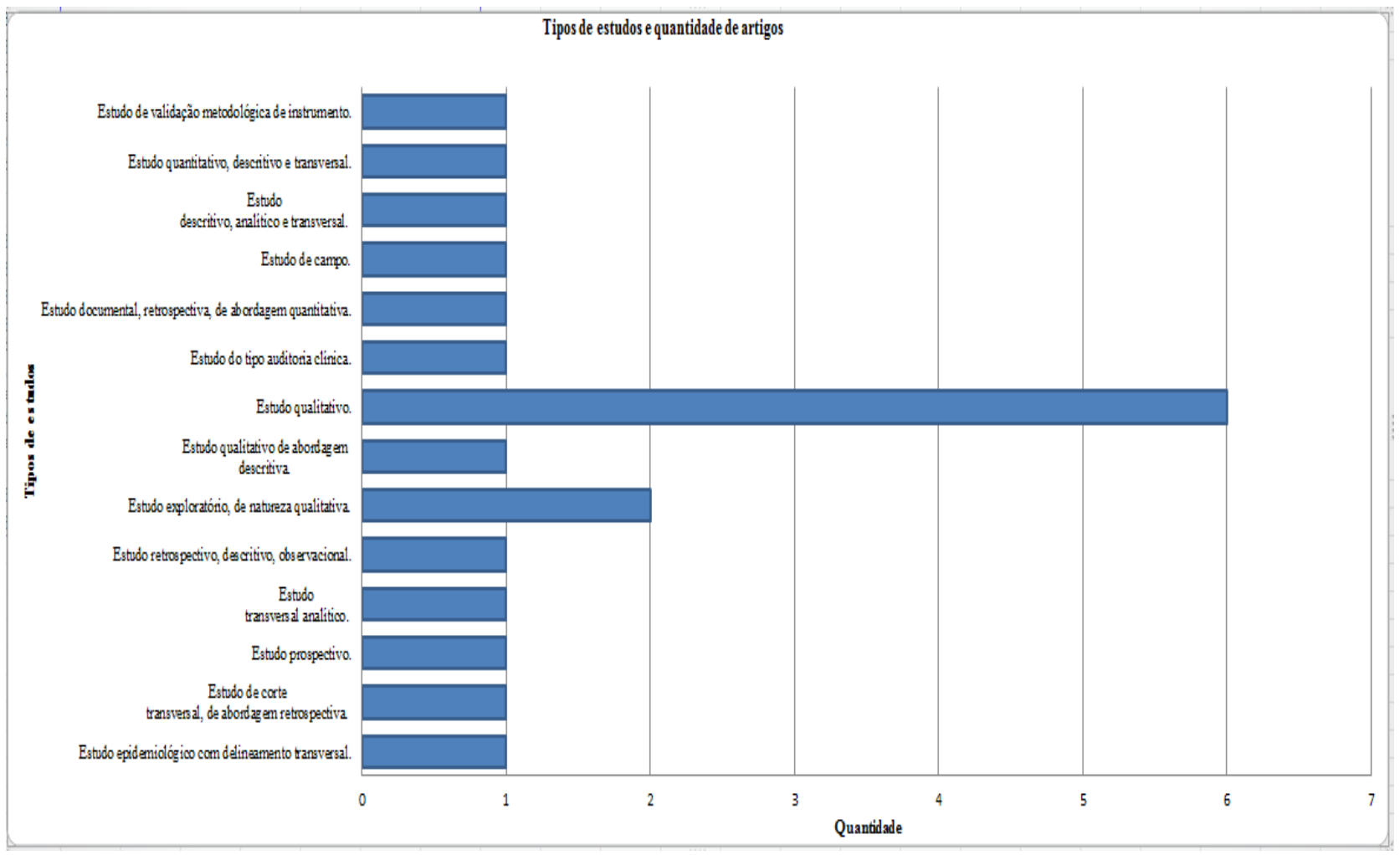

Fonte: Autores (2021).

Ao analisar o Gráfico representado acima, identificam-se os tipos de estudo e a quantidade de artigos publicados. Nota-se que, evidenciou-se um total de: Estudo de validação metodológica de instrumento (1), Estudo qualitativo descritivo transversal (1), Estudo descritivo analítico e transversal (1), Estudo de campo (1), Estudo documental retrospectivo de abordagem quantitativo (1), Estudo do tipo auditoria clínica (1), Estudo qualitativo (6), Estudo qualitativo de abordagem descritiva (1), Estudo exploratório de natureza qualitativa (2), Estudo retrospectivo descritivo observacional (1), estudo transversal analítico (1), Estudo prospectivo (1), Estudo de corte transversal de abordagem retrospectiva (1), Estudo epidemiológico com delineamento transversal (1). Totalizando 20 estudos selecionados na amostra final para construção do presente estudo.

Gráfico 5. Distribuição dos artigos de acordo com as bases de dados e a quantidade de artigos.

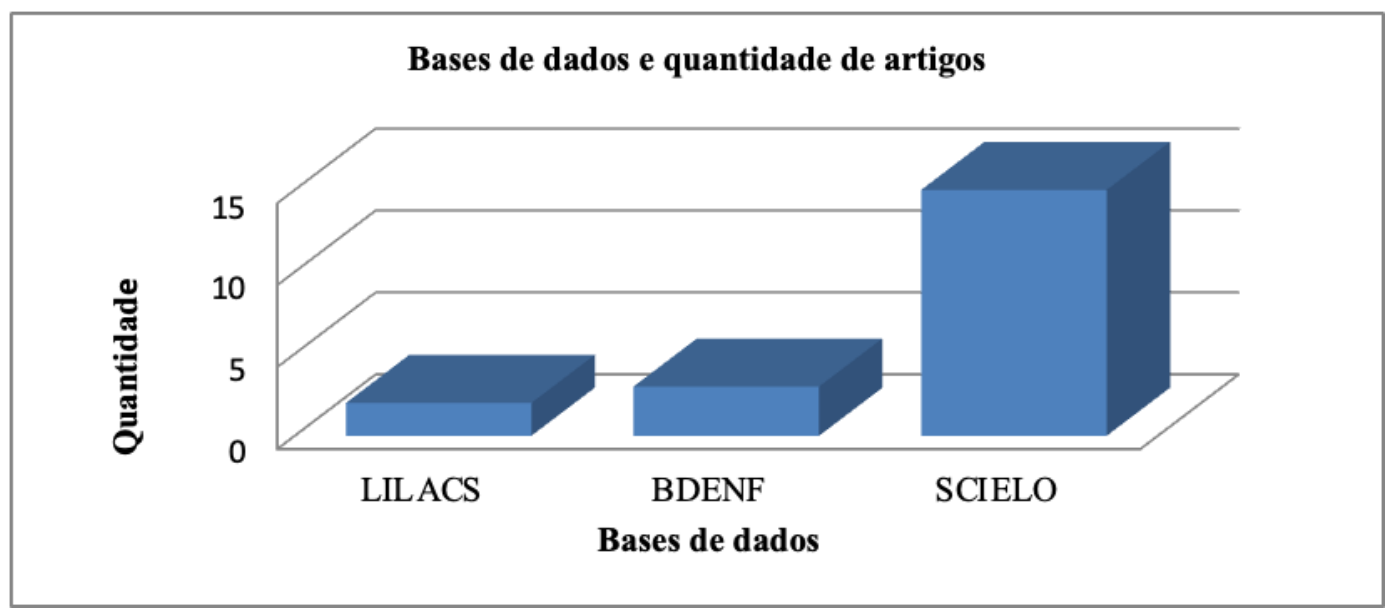

Fonte: Autores (2021). 
Segundo o gráfico representado acima é possível identificar as bases de dados e a quantidade de artigo publicados em cada uma. Nota - se que na Literatura Latino-Americana e do Caribe em Ciências da Saúde (LILACS) ocorreu (2) publicações, Base de Dados de Enfermagem (BDENF), (3) e - Scientific Electronic Library Online (SCIELO) (15). Sendo que foram adotados os critérios metodológicos na elaboração do referido estudo.

Gráfico 6. Distribuição dos artigos de acordo com as bases de dados e a porcentagem de artigos.

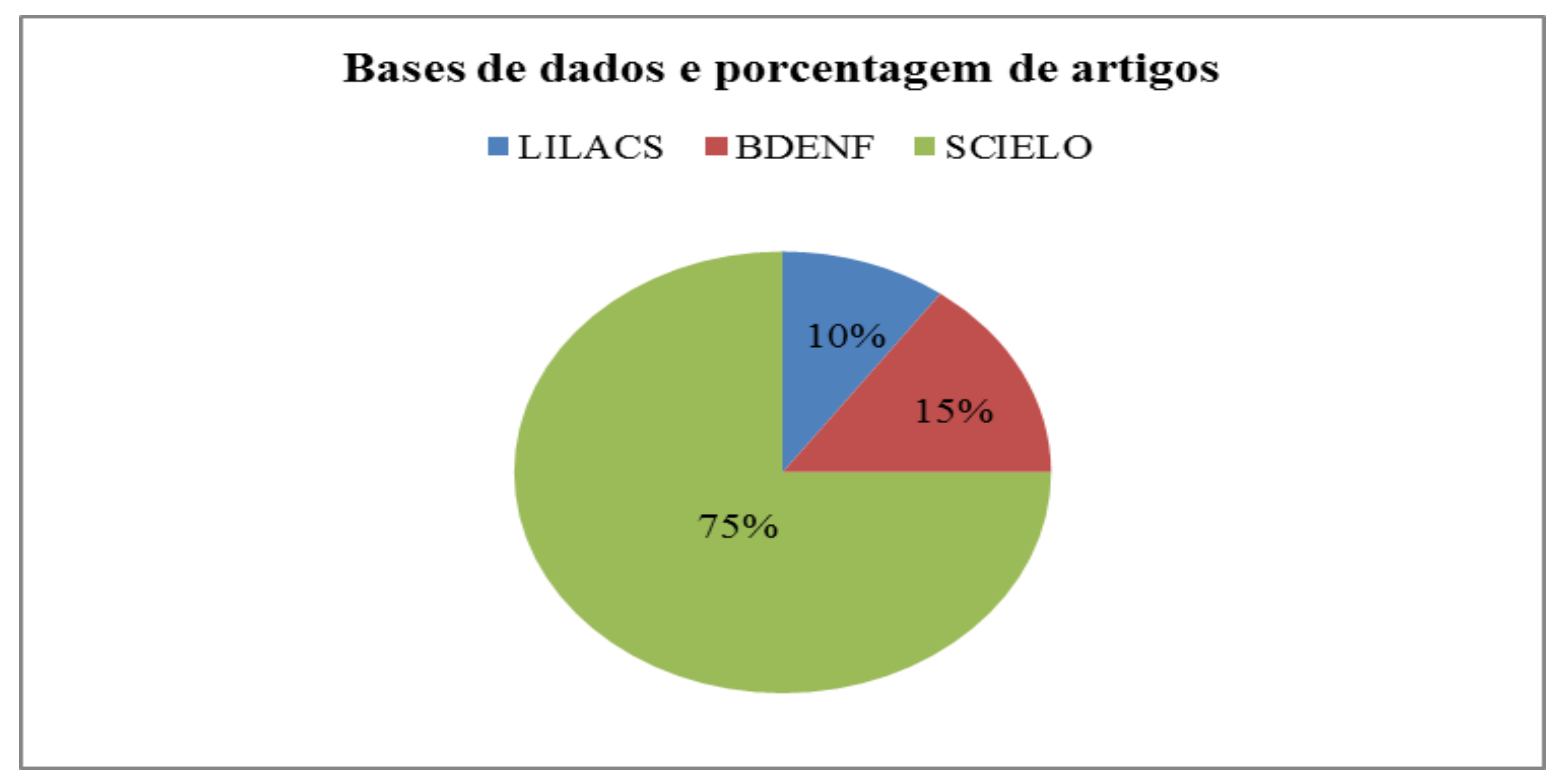

Fonte: Autores (2021).

De acordo com o Gráfico ilustrado acima identifica-se as bases de dados e a porcentagem dos artigo publicados em cada uma. Nota - se que na Literatura Latino-Americana e do Caribe em Ciências da Saúde (LILACS) ocorreu (10\%) das publicações, Base de Dados de Enfermagem (BDENF), (15\%) e - Scientific Electronic Library Online (SCIELO) (75\%). Sendo que foram adotados os critérios metodológicos na elaboração do presente estudo.

As Unidades de Terapia Intensiva (UTIs) são setores designados a prestar assistência de alta complexidade a pacientes em estado crítico de saúde. Quando são admitidos nessas unidades necessitam de tratamento e cuidados específicos e, frequentemente, são expostos a procedimentos invasivos, sendo um dos principais a inserção do Cateter Venoso Central. O CVC é extremamente importante na assistência à saúde. Pelas seguintes indicações: realização de hemodiálise, infusão de nutrição parenteral, quimioterapia, transplante de medula óssea, terapia endovenosa, monitorização hemodinâmica e é essencial para o tratamento e a assistência de enfermagem principalmente em UTI. Intrigante é saber que a taxa de infecção pela corrente sanguínea é significativamente maior em pacientes que utilizam esse dispositivo, como mostrou uma pesquisa realizada pelo Sistema Nacional de Vigilância de Infecções Hospitalares (Neto, Dias, Ribeiro, \& Lima, 2020).

A alta complexidade dos pacientes internados em Unidades de Terapia Intensiva (UTI's), promove maior exposição desses indivíduos às Infecções Relacionadas à Assistência à Saúde (IRAS), por consequência aos fatores que favorecem o processo de infecção, como a realização recorrente de procedimentos invasivos; uso de antimicrobianos e imunossupressores; o ambiente potencialmente contaminado e o próprio quadro clínico do paciente. As IRAS são eventos adversos considerados problemas de saúde pública, uma vez que é um evento que impacta na segurança da assistência e constitui um importante desafio mundial para o cuidado em saúde. Dessa forma, faz-se necessário agir com medidas preventivas antes da inserção do CVC, durante a inserção, na fixação, estabilização e manutenção do dispositivo em questão (Faria et al., 2021). 
Segundo a Sociedade Brasileira de Enfermeiros de Terapia Intensiva, frequentemente, a remoção do cateter é realizada quando termina a terapia proposta, devido à ruptura, quebra ou posicionamento inadequado, extravasamento de líquidos, presença de processo infeccioso ou, ainda, quando houver um processo inflamatório. Assim, cabe ao enfermeiro identificar qual é o motivo da remoção e descontinuar a terapia. O enfermeiro responsável deve, ainda, ser muito cauteloso quanto à manutenção do cateter, bem como treinar sua equipe para que realize com total atenção todos os procedimentos relacionados a esse, ter uma observação prudente, evitando proliferação ou risco de infecções. A ponta do cateter deve estar localizada na veia cava. O mau posicionamento pode ocasionar pneumotórax, hidrotórax, hemotórax, hidromediastino, fístula arteriovenosa, perfuração cardíaca e tamponamento, entre outros (Gonçalves, Farias, \& Ribeiro, 2013).

Atualmente, a sepse é uma síndrome clínica que representa uma das maiores causas de hospitalização e mortalidade em Unidades de Terapia Intensiva (UTI), apesar da disponibilidade dos modernos recursos diagnósticos, do uso de antibióticos de largo espectro, da monitorização hemodinâmica à beira do leito, do controle metabólico intensivo e dos novos recursos terapêuticos. Além disso, ela se manifesta em distintos espectros de gravidade com o decorrer do tempo, caso não seja prontamente diagnosticada e tratada, representando altos custos anuais em seu tratamento (Neto, Barros, Oliveira, Fontes, \& Nóbrega, 2011).

As Infecções relacionadas à Assistência à Saúde (IRAS) atingem com frequência os sistemas de saúde, constituindose como um grave problemas de saúde pública mundial, elevando os custos hospitalares e os índices de morbidade e mortalidade entre os pacientes. As IRAS são definidas como toda e qualquer infecção que acomete o indivíduo, seja em instituições hospitalares, seja em atendimentos ambulatoriais na modalidade de hospital dia ou domiciliar, e que possa estar associada a algum procedimento assistencial, seja ele terapêutico ou diagnóstico. Assim, com a introdução de novos métodos diagnósticos e terapêuticos e o avanço tecnológico na assistência à saúde, aumentam-se as possibilidades de intervenção e diminuição da mortalidade. Entretanto, tal avanço traz um aumento do risco de IRAS e deste modo controlar a ocorrência dessas infecções é uma tarefa desafiadora (Rodriguês, \& Pereira, 2016).

Nas Unidades de Terapia Intensiva (UTI), as IRAS estão associadas principalmente ao uso de procedimentos invasivos (cateteres venosos centrais, sondas vesicais de demora, ventilação mecânica e outros), imunossupressores; prolongado período de internação, colonização por microrganismos resistentes, uso indiscriminado e abusivo de antimicrobianos e o próprio ambiente da unidade que já favorece a seleção natural de microrganismos e, consequentemente a colonização e/ou infecção pelos mesmos, inclusive os microrganismos multirresistentes. Um fator de risco para infecção hospitalar é simplesmente um indicador de risco, ou um fator associado à infecção hospitalar. Tal indicador de risco não precisa necessariamente ser a causa da infecção ou preceder a infecção. De acordo com a Lei no 7498 de 25 de junho de 1986 , que dispôs sobre a regulamentação do exercício da Enfermagem, cabe ao enfermeiro, enquanto integrante da equipe de saúde, a prevenção e o controle sistemático da infecção nosocomial e de doenças transmissíveis em geral (Rodriguês, \& Pereira, 2016).

O risco de infecção por acesso vascular está diretamente relacionado à localização do acesso vascular, da solução infundida, experiência do profissional que realiza o procedimento, tempo de permanência, tipo e manipulação do cateter, dentre outros. Estes fatores estão relacionados aos pontos principais para o desenvolvimento de ações preventivas para tal infecção. O enfermeiro é a figura chave no controle de infecções hospitalares, sendo sua presença indispensável para a realização das tarefas básicas do controle de infecções. Portanto, o papel do enfermeiro, é de extrema importância na prevenção e controle das infecções hospitalares, participando em todo o processo. Por isso, se faz necessário a presença de profissionais atuantes e determinados no propósito de treinar outros profissionais da área em serviço, preconizando e enfatizando que prevenir é controlar, e dessa forma se reduz tempo de permanência dos usuários nos hospitais, custo em medicações e até mesmo tempo de trabalho (Jesus, Alves, \& Valente, 2012). 
Os principais fatores de risco associados às IH são os relacionados às intervenções diagnósticas e terapêuticas, sendo os mais frequentes: cateterização urinária, os cateteres venosos, prótese em via aérea por tempo prolongado (intubações, traqueostomias e ventilação mecânica), os cateteres para monitorização de pressão venosa central, pacientes com doenças crônicas e os traumatizados, além do tempo de permanência hospitalizado. Os fatores de risco usualmente implicados na ventilação mecânica prolongada, como insuficiência respiratória, disfunção neurológica e presença de traqueostomia foram significativamente associados à infecção em UTI (Sossai, \& Almeida, 2011).

$\mathrm{O}$ uso dos cateteres vasculares centrais vem aumentando com a modernização da medicina, atualmente são de fundamental importância para a administração de fluidos, eletrólitos, sangue, hemoderivados, drogas e nutrição parenteral bem como para a monitoração hemodinâmica invasiva. Porém, a ocorrência de infecções é bastante elevada, podendo variar de infecção local e tromboflebite séptica a infecções sistêmicas como endocardite, osteomielites e endoftalmites. Grande parte das IH está relacionada ao uso de dispositivos vasculares, estando associadas a aumento de mortalidade, ao tempo de permanência no hospital e ampliação dos custos assistenciais. O acesso mais utilizado nas UTI é o venoso central, responsável por cerca de 90\% de todas as infecções relacionadas a dispositivos vasculares. Quando estes cateteres são inseridos perifericamente são associados a menor incidência de complicações mecânicas e infecciosas, podendo ser utilizados com segurança por um tempo mais prolongado (Sossai, \& Almeida, 2011).

As infecções hospitalares são as principais causas de morte nas unidades de terapia intensiva, representando uma ampliação no tempo de internação, além de um custo elevado para as instituições, por agregar inúmeros fatores de risco como: condições clínicas desfavoráveis, comorbidades, uso de técnicas invasivas e alterações na microbiota. A assistência aos pacientes críticos requer a inevitável aplicação de procedimentos invasivos e a administração de antimicrobianos de amplo espectro, sendo importante assim a redobrada atenção de todos os profissionais envolvidos quanto ao uso de técnicas cada vez mais assépticas, a lavagem rotineira das mãos e o uso controlado e estritamente necessário de técnicas invasivas e de antibióticos na rotina dos cuidados. Fica clara a importância de programas de prevenção e da incorporação e correto funcionamento das Comissões de Controle de Infecção Hospitalar nas instituições de saúde, para, dessa forma, diminuir a ocorrência de infecções hospitalares e também a diminuição de mortes e dos altos custos quanto ao tratamento desses pacientes (Sossai, \& Almeida, 2011).

De acordo com Fernandes et al. (2018), o enfermeiro como líder da equipe de enfermagem deve obter conhecimento amplo quanto à sepse, com propósito em planejar o cuidado habilidosamente, garantir segurança na tomada de decisões e implantar intervenções com finalidade no reconhecimento em menor tempo possível para evolução de um prognóstico mais favorável.

Nesse sentido, a sepse é uma patologia que representa causa relevante de hospitalização e mortalidade em unidades de terapia intensiva, se manifesta em níveis gravíssimos e com o tempo, sendo necessária visão amplamente crítica para prontamente diagnosticar e tratar o paciente. Assim, é importante a efetivação dos protocolos e critérios referenciados pelos órgãos de saúde com finalidade em reduzir a sepse nas internações hospitalares, bem como, manter constantemente o aperfeiçoamento em saúde sobre meios tecnológicos, científicos, incorporação dos conceitos, e assistência humanizada, pois através de uma assistência qualificável, previnem-se custos elevados com terapias e subsequentemente garante-se um restabelecimento mais rápido e seguro do paciente séptico. Desta forma, o enfermeiro em terapia intensiva, através do saber peculiar vem sendo realce diante da complexidade que permeia nesta área. Com tantos avanços, a equipe de enfermagem deve acompanhar esta evolução e requerer assim enfermeiros preparados para lidar com essa demanda e ambiente complexo. Portanto, todos os enfermeiros devem estar inteirados que a atuação diante do paciente séptico exige condutas ágeis, precisas e padronizadas de acordo com as regras institucionais e literatura científica pertinente (Fernandes et al., 2018). 
Desse modo, enfermeiros são profissionais ímpares para proporcionar um bom planejamento do cuidado com pacientes sépticos, pois são mediadores de condutas e intervenções entre a equipe de saúde, todavia ainda são restritas as pesquisas que aproximam a atuação do enfermeiro frente ao diagnóstico de sepse em pacientes de terapia intensiva. Por fim, acredita-se que é de suma importância utilizar-se do melhor conhecimento embasado em práticas e evidências científicas, com finalidade em prover uma assistência cada vez mais qualificada, enriquecer ainda mais o cuidado e exercer a enfermagem com excelência profissional mediante os pacientes acometidos por essa patologia em função do melhor prognóstico e sobrevida destes pacientes (Fernandes et al., 2018).

\section{Conclusão}

Evidenciou-se no estudo, que a sepse é considerada uma das principais causas de morte em Unidades de Terapia Intensiva (UTI’s). No Brasil, a taxa de mortalidade e letalidade são preocupantes, principalmente nos hospitais públicos vinculados ao Sistema Único de Saúde (SUS). Um estudo conduzido pelo ILAS apontou que 30\% dos leitos de 229 UTI's brasileiras estão ocupados por pacientes com sepse ou choque séptico e que a letalidade nestes pacientes ultrapassa os $50 \%$. Esses dados revelam o alto custo da sepse, tanto no que diz respeito aos gastos econômicos quanto à quantidade de vidas perdidas.

Assim, a atuação precisa do enfermeiro, mediante a identificação de padrões anormais de saúde e o reconhecimento precoce constitui-se uma das principais formas de aplicação dos cuidados de enfermagem, tendo em vista que, após instalação da doença, quanto mais precisa e rápida ocorrer às ações de saúde, menores serão as chances de progressão e gravidade da doença e, consequentemente, melhor será o prognóstico.

Nesse sentido, em virtude da relevância do tema, torna-se fundamental o aumento do número de estudos realizados na área. Além disso, é importante que protocolos assistenciais para o manejo da sepse sejam implementados ainda na unidade de origem dos pacientes, bem como na UTI, pois conferem maior agilidade e, consequentemente, maior segurança assistencial, evitando assim o agravamento e o óbito dos mesmos.

Diante desse contexto, faz-se necessário que toda a equipe multidisciplinar tenha total conhecimento no processo de identificação precoce dos sinais e sintomas da sepse. Ademais, para se ter um bom prognóstico e, consequentemente, minimizar possíveis consequências, é imprescindível também a prestação imediata da assistência.

Entende-se que a prevenção das IRAS relacionada ao uso do dispositivo de CVC em pacientes de UTI requer colaboração e participação de todas as equipes de saúde que assistem o usuário de forma direta e indiretamente é um fato concreto. Isto inclui desde o reconhecimento da importância de prevenção por parte da equipe administrativa incentivando e possibilitando que treinamentos, educação em saúde, criação de protocolos, bundles e aquisição de material de qualidade tecnológica, até a execução de cada ação proposta pelas equipes que mantém contato direto com o paciente.

Dessa forma, a redução das infecções relacionadas às IRAS é uma recomendação da Organização Mundial da Saúde (OMS), e cobrada pelo Ministério da Saúde. Assim torna-se relevante o conhecimento científico sobre os tipos de CVC, suas indicações, seu manuseio adequado e também a qualificação dos profissionais que irão prestar assistência, bem como que irão manipular o usuário.

\section{Referências}

Aguiar, K. V. D. C. S., da Cunha Cruz, R., de Araújo Silva, R. T., de Sousa, C. F. C., \& Moraes, K. L. D. C. S. (2020). Sepse em Unidade de Terapia Intensiva: Fatores Predisponentes e a Atuação Preventiva do Enfermeiro/Sepse in Intensive Care Unit: Predisponent Factors and Preventive Nursing Acting. ID on line Revista de psicologia, 14(52), 214-230. 
Araújo Freitas, M. F., Picanço, C. M., de Assis, Y. I., \& da Hora Assis, M. P. (2021). Fatores associados ao desenvolvimento de sepse em pacientes internados em terapia intensiva cirúrgica: estudo retrospectivo/Factors associated with the development of sepsis in patients hospitalized in intensive surgical therapy: a retrospective study. Ciência, Cuidado e Saúde, 20.

Augusto, C. A., Souza, J. P. D., Dellagnelo, E. H. L., \& Cario, S. A. F. (2013). Pesquisa Qualitativa: rigor metodológico no tratamento da teoria dos custos de transação em artigos apresentados nos congressos da Sober (2007-2011). Revista de Economia e Sociologia Rural, 51(4), 745-764.

Barros, L. L. D. S., Maia, C. D. S. F., \& Monteiro, M. C. (2016). Fatores de risco associados ao agravamento de sepse em pacientes em Unidade de Terapia Intensiva. Cadernos Saúde Coletiva, 24, 388-396.

BORGES, T. B. R. D. (2018). Atuação do enfermeiro frente ao risco de infecção com cateter venoso central na Unidade de Terapia Intensiva.

Botelho, L. L. R., de Almeida Cunha, C. C., \& Macedo, M. (2011). O método da revisão integrativa nos estudos organizacionais. Gestão e sociedade, 5(11), 121-136.

Carvalho, R. H. D., Vieira, J. F., Gontijo Filho, P. P., \& Ribas, R. M. (2010). Sepse, sepse grave e choque séptico: aspectos clínicos, epidemiológicos e prognóstico em pacientes de Unidade de Terapia Intensiva de um Hospital Universitário. Revista da Sociedade Brasileira de Medicina Tropical, 43 , $591-593$.

Faria, R. V., Gomes, A. L., Brandão, A. C., de Paula Silveira, C., Silva, C. P. R., Monteiro, L. A. S., ... \& Takeshita, I. M. (2021). Infecção de corrente sanguínea relacionada a cateter venoso central: avaliação dos fatores de riscos. Brazilian Journal of Health Review, 4(3), 10143-10158.

Ferenhof, H. A., \& Fernandes, R. F. (2016). Desmistificando a revisão de literatura como base para redação científica: método SSF. Revista ACB, 21(3), 550563.

Fernandes, A. M. G., de Melo Soares, G. T., da Silva Nascimento, L. K. A., da Silva Pellense, M. C., de Lima Carvalho, G. A. F., \& de Sena, D. C. S. (2018). Atuação da enfermagem na detecção precoce e tratamento da sepse na terapia intensiva. Revista humano ser, 3(1).

Jesus, P. B. R., Alves, E. M. C., \& Valente, G. S. C. Prevenção e controle de infecção relacionada a cateter venoso central.

Luz Filho, C. A., \& Marinho, C. M. M. (2019). Fatores de risco em pacientes com sepse em unidades de terapia intensiva. Revista Eletrônica Acervo Saúde, (19), e208-e208.

Martins, M. V., Sandim, L. S., Felipe, A. C. C., \& de Sousa, M. J. (2020). Fatores de riscos que contribuem para sepse relacionada ao cateter venoso central em unidades de terapia intensiva. Brazilian Journal of Development, 6(5), 31512-31530.

Mendes, K. D. S., Silveira, R. C. D. C. P., \& Galvão, C. M. (2008). Revisão integrativa: método de pesquisa para a incorporação de evidências na saúde e na enfermagem. Texto \& contexto enfermagem, 17(4), 758-764.

Neto, J. M. R., Campos, D. A., de Araújo Marques, L. B., Ramalho, C. R. D. O. C., \& da Nóbrega, M. M. L. (2015). Concepções de enfermeiros que atuam em unidade de terapia intensiva geral sobre sepse. Cogitare Enfermagem, 20(4).

Neto, J. M. R., de Barros, M. A. A., de Oliveira, M. F., de Fontes, W. D., \& da Nóbrega, M. M. L. (2011). Assistência de enfermagem á pacientes sépticos em uma unidade de terapia intensiva adulto. Revista de Ciências da Saúde Nova Esperança, 9(2), 18-27.

Neto, L. V., Dias, M. G. G., Ribeiro, M. C. M., \& Lima, R. N. (2020). Prevenção e controle de infecções: cateter venoso central em unidade de terapia intensiva adulto. Revista Brasileira Interdisciplinar de Saúde.

Pedrosa, K. K. D. A., Oliveira, S. A. D., \& Machado, R. C. (2018). Validação de protocolo assistencial ao paciente séptico na Unidade de Terapia Intensiva. Revista Brasileira de Enfermagem, 71(3), 1106-1114.

Pereira, A. S., Shitsuka, D. M., Parreira, F. J., \& Shitsuka, R. (2018). Metodologia da pesquisa científica.

Reiner, G. L., Vignardi, D., Da Gama, F. O., Vietta, G. G., \& Klingelfus, F. S. (2020). Desfecho clínico e fatores associados ao óbito em pacientes com sepse internados em unidade de terapia intensiva. Arquivos Catarinenses de Medicina, 49(1), 02-09.

Rodrigues, C. N., \& Pereira, D. C. A. (2016). Infecções relacionadas à assistência à saúde ocorridas em uma Unidade de Terapia Intensiva. Revista de Investigação Biomédica, 8(1), 41-51.

Silva, A. G., \& de Oliveira, A. C. (2016). Prevenção da infecção da corrente sanguínea relacionada ao cateter venoso central: Uma revisão integrativa. Vigilância Sanitária em Debate: Sociedade, Ciência \& Tecnologia (Health Surveillance under Debate: Society, Science \& Technology)-Visa em Debate, 4(2), 117-125.

Soares, C. B., Hoga, L. A. K., Peduzzi, M., Sangaleti, C., Yonekura, T., \& Silva, D. R. A. D. (2014). Revisão integrativa: conceitos e métodos utilizados na enfermagem. Revista da Escola de Enfermagem da USP, 48(2), 335-345.

Sossai, L. M., \& de Almeida, C. L. Infecção hospitalar na unidade de terapia intensiva: fatores de risco e mortalidade1 the hospital infection in the intensive care unit: risk factors and mortality.

Sousa, C. M. D. S., Mascarenhas, M. D. M., Gomes, K. R. O., Rodrigues, M. T. P., Miranda, C. E. S., \& Frota, K. D. M. G. (2020). Ideação suicida e fatores associados entre escolares adolescentes. Revista de Saúde Pública, 54, 33.

Sousa, F. C., Pereira, J. C., de Andrade Rezende, D., \& Laura, C. (2018). Avaliação dos cuidados de enfermagem com o cateter venoso central em uma unidade de terapia intensiva adulto e pediátrica. Revista de Administração em Saúde, 18(70).

Sousa, J. F., de Carvalho Sousa, V., de Carvalho, C. M. S., Amorim, F. C. M., Fernandes, M. A., Coelho, M. C. V. S., \& Soares, J. (2019). Prevenção ao suicídio na atenção básica: concepção de enfermeiros. Revista Cuidarte, 10(2), 4. 
Research, Society and Development, v. 10, n. 16, e08101622853, 2021

(CC BY 4.0) | ISSN 2525-3409 | DOI: http://dx.doi.org/10.33448/rsd-v10i16.22853

Sousa, L. M. M., Marques-Vieira, C. M. A., Severino, S. S. P., \& Antunes, A. V. (2017). A metodologia de revisão integrativa da literatura em enfermagem. No21 Série 2-Novembro 2017, 17.

Souza, M. T. D., Silva, M. D. D., \& Carvalho, R. D. (2010). Revisão integrativa: o que é e como fazer. Einstein (São Paulo), 8(1), $102-106$.

Todeschini, A. B., \& Trevisol, F. S. (2011). Sepse associada ao cateter venoso central em pacientes adultos internados em unidade de terapia intensiva. Rev Bras Clin Med. São Paulo, 9(5), 334-7. 